\title{
Carbonic anhydrase XII is a new therapeutic target to overcome chemoresistance in cancer cells
}

\author{
Joanna Kopecka ${ }^{1, *}$, Ivana Campia ${ }^{1, *}$, Andrea Jacobs ${ }^{2}$, Andreas P. Frei ${ }^{2,3}$, Dario Ghigo ${ }^{1}$, \\ Bernd Wollscheid ${ }^{2,3}$, Chiara Riganti ${ }^{1}$ \\ ${ }^{1}$ Department of Oncology, University of Torino, 10126 Torino, Italy \\ ${ }^{2}$ Department of Biology, Institute of Molecular Systems Biology, Swiss Federal Institute of Technology (ETH) Zurich, 8093 \\ Zurich, Switzerland \\ ${ }^{3}$ Biomedical Proteomics Platform (BMPP), Department of Health Sciences and Technology, Swiss Federal Institute of \\ Technology (ETH) Zurich, 8093 Zurich, Switzerland \\ "These authors have contributed equally to this work \\ Correspondence to: \\ Chiara Riganti, e-mail: chiara.riganti@unito.it \\ Keywords: chemoresistance, surfaceome, P-glycoprotein, carbonic anhydrase type XII \\ Received: September 09, 2014 \\ Accepted: December 09, 2014 \\ Published: February 18, 2015
}

\section{ABSTRACT}

Multidrug resistance (MDR) in cancer cells is a challenging phenomenon often associated with P-glycoprotein (Pgp) surface expression. Finding new ways to bypass Pgp-mediated MDR still remains a daunting challenge towards the successful treatment of malignant neoplasms such as colorectal cancer.

We applied the Cell Surface Capture technology to chemosensitive and chemoresistant human colon cancer to explore the cell surface proteome of Pgpexpressing cells in a discovery-driven fashion. Comparative quantitative analysis of identified cell surface glycoproteins revealed carbonic anhydrase type XII (CAXII) to be up-regulated on the surface of chemoresistant cells, similarly to Pgp. In cellular models showing an acquired MDR phenotype due to the selective pressure of chemotherapy, the progressive increase of the transcription factor hypoxia-inducible factor-1 alpha was paralleled by the simultaneous up-regulation of Pgp and CAXII. CAXII and Pgp physically interacted at the cell surface. CAXII silencing or pharmacological inhibition with acetazolamide decreased the ATPase activity of Pgp by altering the optimal pH at which Pgp operated and promoted chemosensitization to Pgp substrates in MDR cells.

We propose CAXII as a new secondary marker of the MDR phenotype that influences Pgp activity directly and can be used as a pharmacological target for MDR research and potential treatment.

\section{INTRODUCTION}

One of the main features of chemoresistant cancer cells is the high cell surface expression of ATP binding cassette $(\mathrm{ABC})$ transporters, such as P-glycoprotein (Pgp/ $A B C B 1$ ), multidrug resistance (MDR) related proteins (MRPs/ABCCs) and breast cancer resistance protein (BCRP/ABCG2). These plasma membrane transporters enable the active transport of chemotherapeutic drugs into the extracellular space, ultimately reducing intracellular concentrations, cytotoxicity, and therapeutic success [1-3]. Pgp is one of the ABC transporters with the broadest spectrum of substrates, which include anthracyclines, taxanes, Vinca alkaloids, epipodophyllotoxins, topotecan, methotrexate, imatinib, dasatinib, lapatinib, gefitinib, sorafenib, and erlotinib. As a consequence, tumors overexpressing Pgp often exhibit a MDR phenotype and are difficult to eradicate by chemotherapy $[1,4]$.

In attempts to overcome chemoresistance, $\mathrm{ABC}$ transporters have been targeted with pharmacological inhibitors. However, such approaches have led to several therapeutic failures due to the widespread tissue distribution of $\mathrm{ABC}$ transporters. Moreover, since $\mathrm{ABC}$ transporters play critical functions in the physiological clearance of catabolites and xenobiotics [5-7], their pharmacological inhibition 
produces toxicities in vivo. Thus, pharmacological targeting of other surface proteins that are selectively overexpressed in chemoresistant cells and modulate the activity of ABC transporters is a promising alternative approach.

Until now, only few studies have analyzed the surfaceome of chemoresistant cells $[8,9]$. These studies have identified proteins that were overexpressed in MDR cells, such as CD44 [8], dihydropyridine receptor alpha 2 and laminin subunit alpha 5 [9]. These cell surface proteins could be of clinical utility as potential biomarkers predictive of chemoresistance and/or potential therapeutic targets. However, these proteins were not found to modulate the expression or activity of Pgp or other ABC transporters in MDR cells, making them unlikely targets for the suppression of the MDR phenotype.

Pgp activity is finely modulated by the plasmamembrane lipid composition and physicochemical parameters [10]. A considerable number of proteins have been reported to physically interact with Pgp, such as the E3 ubiquitin ligases RNF2 [11] and FBXO15 [12], the endoplasmic reticulum-associated chaperon calreticulin [13], the serine/threonine kinase Pim-1 [14], the estrogen receptor repressor prohibitin 2 [15], the transcription factor Myc [16], the surface molecules caveolin-1 [17] and CD4 [18], the BRCA2 and CDKN1A-interacting protein BCCP, the Target of Rapamycin complex 2 subunit MAPKAP1 [18], and the lysosomal-associated protein LAPTM4B-35 [19]. Among these interactors, caveolin-1 [17] and RNF2 [11] negatively modulate Pgp activity, whereas LAPTM-35 is the only protein that has been shown to increase Pgp activity [19].

Here, we applied the Cell Surface Capturing (CSC) technology to investigate the surfaceome of a Pgp-negative (chemosensitive) and Pgp-positive (chemoresistant) human colon cancer model system, with the goal to identify quantitative surfaceome changes indicative of chemoresistance. This analysis identified carbonic anhydrase type XII (CAXII; accession number O43570, UniProtKB; http://www.uniprot.org) as a protein with significantly higher expression on the surface of chemoresistant cells. Based on this finding, we investigated whether changes in CAXII cell surface abundance were able to induce and/or maintain the MDR phenotype and whether CAXII could potentially be exploited as therapeutic target to chemosensitize MDR cells.

\section{RESULTS}

\section{CAXII shows a higher cell surface abundance in chemoresistant cells than in chemosensitive cells}

CSC technology, which selectively tags and purifies cell surface exposed glycopeptides for analysis by mass spectrometry, enabled the identification of 380 cell surface residing glycoproteins from human chemosensitive colon cancer HT29 cells and human chemoresistant colon cancer
HT29/dx cells. The functional classification of the identified proteins is shown in Figure 1A. The quantitative analysis of cell surface protein expression in HT29/dx and in HT29 cells is reported in Figure 1B and in Supplemental Table 1.

Among the ABC transporters detected on the surface of chemoresistant cells, ABCC1/MRP1 was more abundant on HT29/dx cells, and ABCC3/MRP3, ABCA1, ABCA2 showed lower expression levels. One of the proteins with highest relative expression in chemoresistant cells was CAXII, which was 16-fold more expressed in HT29/dx cells than in parental HT29 cells (Figure 1B and Supplemental Table 1). CAXII topology and identified glycopeptides are shown in Supplemental Figure 1. These data were confirmed by confocal microscopy analysis (Figure 2A) and by immunoblot analysis of biotinylated extracts from HT29 and HT29/dx cells (Figure 2B). Biotinylation assays confirmed that Pgp and MRP1 were more abundant on the surface of HT29/dx compared to HT29 cells (Figure 2B). The ratio of N-glycosylated to deglycosylated Pgp in plasma membrane extracts was about 1 in HT29/dx cells, whereas the ratio of $\mathrm{N}$-glycosylated to deglycosylated MRP1 was higher than 1 (Supplemental Figure 2A and 2B).

The higher surface abundance level of CAXII was not due to differential trafficking, since intracellular pools of CAXII were also elevated in HT29/dx whole cell lysate (Figure 2C). This phenomenon was not specific to colon cancer cells and higher levels of CAXII were also found in chemoresistant lung cancer A549/dx cells compared to chemosensitive A549 cells (Figure 2C). Similarly, a comparison of U2-OS cells with corresponding doxorubicin-resistant clones (U2-OS/dx 30, U2-OS/ $\mathrm{dx} 100, \mathrm{U} 2-\mathrm{OS} / \mathrm{dx}$ 580) revealed that CAXII levels also correlated with chemoresistance in these osteosarcoma cells (Figure 2C). All tested chemoresistant cell lines had higher expression of Pgp than the corresponding chemosensitive cells; HT29/dx and A549/dx cells also had higher levels of MRP1, which was undetectable in the chemoresistant osteosarcoma cells (Figure 2C). On the basis of these results, we found a strong direct correlation between CAXII and Pgp expression (Figure 2D); no correlation was found for CAXII and MRP1 expression (not shown). According to tissues expression data, CAXII and Pgp (Supplemental Figure 3 and 4), but not CAXII and MRP1 (Supplemental Figure 3 and 5), were expressed at similar levels in colon adenocarcinoma samples.

\section{CAXII expression increases during the acquisition of chemoresistance, in parallel with the increase of HIF-1 $\alpha$ and Pgp}

The difference in CAXII protein expression between HT29 and HT29/dx cells was paralleled by a striking difference in mRNA levels (Figure 3A). Upstream regulatory regions of the CAXII gene contain hypoxiaresponse element (HRE) sequences [20], suggesting that the 
A

receptors
transporters
hydrolases
cell adhesion molecules
transferases
signaling molecules
proteases
defense/immunity proteins
extracellular matrix proteins
enzyme modulators
oxidoreductases
transfer/carrier proteins
phosphatases
membrane traffic proteins
calcium-binding proteins
chaperones
kinases
lyases
cytoskeletal proteins
cell junction proteins
isomerases
ligases
transmembrane receptors
nucleic acid bindings
structural proteins
transcription factors

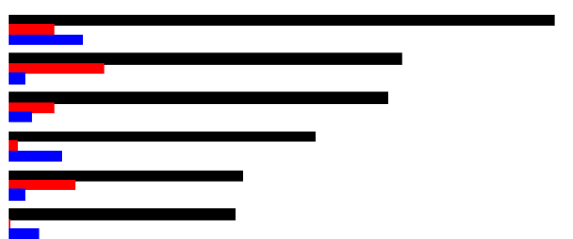
defense/immunity proteins extracellular matrix proteins nzyme modulators oxidoreductases
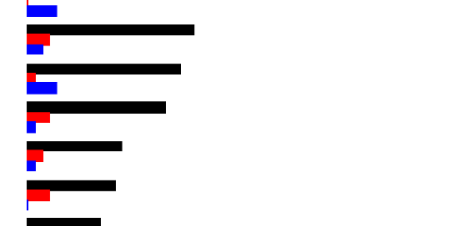

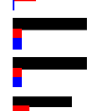

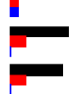

F

r

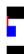

- Proteins up-regulated in HT29

Proteins up-regulated in HT29/dx

Proteins identified in HT29 and HT29/dx

$\begin{array}{llllllllll}0 & 10 & 20 & 30 & 40 & 50 & 60 & 70 & 80 & 90\end{array}$

B

Quantitative changes in $\mathrm{HT} 29 / \mathrm{dx} / \mathrm{HT} 29$ proteins ratio
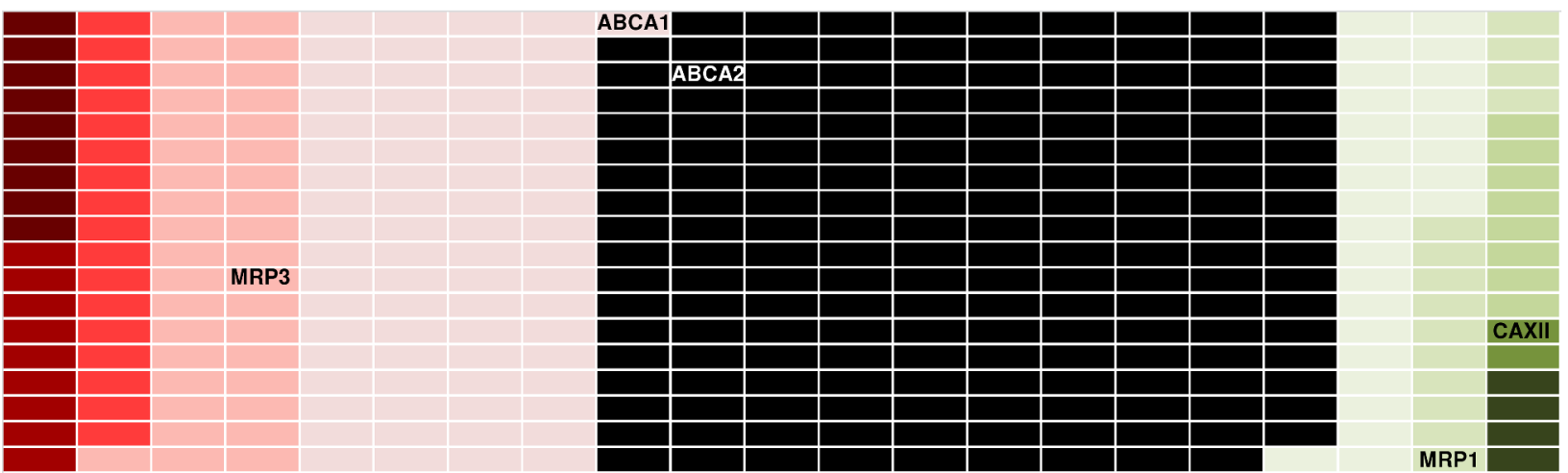

$\log 2$
$(\mathrm{HT} 29 / \mathrm{d} x$

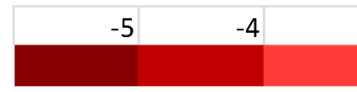

$-3$

$-2$

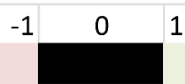

2

3

4

5

/HT29 ratio)

Figure 1: CSC technology enables the identification and quantitative comparison of the surface glycoproteome of human chemosensitive and chemoresistant colon cancer cells. (A) 380 identified plasma membrane-associated proteins (black bars) from human chemosensitive colon cancer HT29 cells and human chemoresistant colon cancer HT29/dx cells were categorized according to the biological function assigned by the PANTHER algorithm. (B) Quantitative analysis of the proteins detected by CSC technology. The ratio between protein expressed in HT29/dx cells and protein expressed in HT29 cells is represented by a colorimetric logarithmic scale. CAXII, ABCC1/MRP1, ABCC3/MRP3, ABCA1 and ABCA2 hits are indicated. 

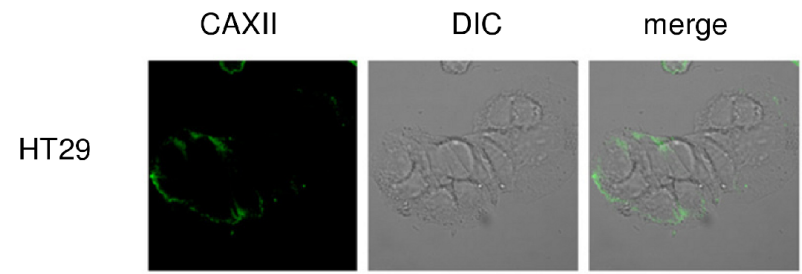

HT29

$/ \mathrm{dx}$
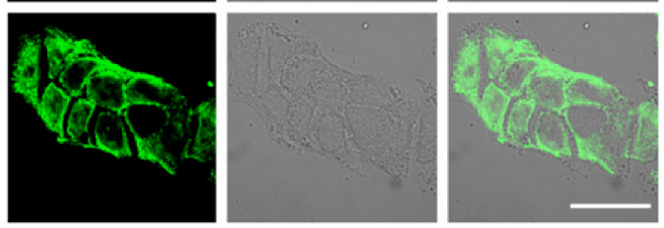

C

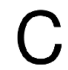

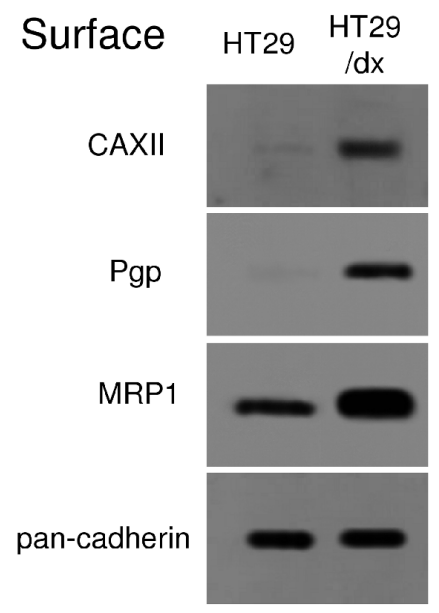

U2OS U2OS U2OS U2OS

$/ \mathrm{d} \times 30 \quad / \mathrm{d} \times 100 \quad / \mathrm{d} \times 580$
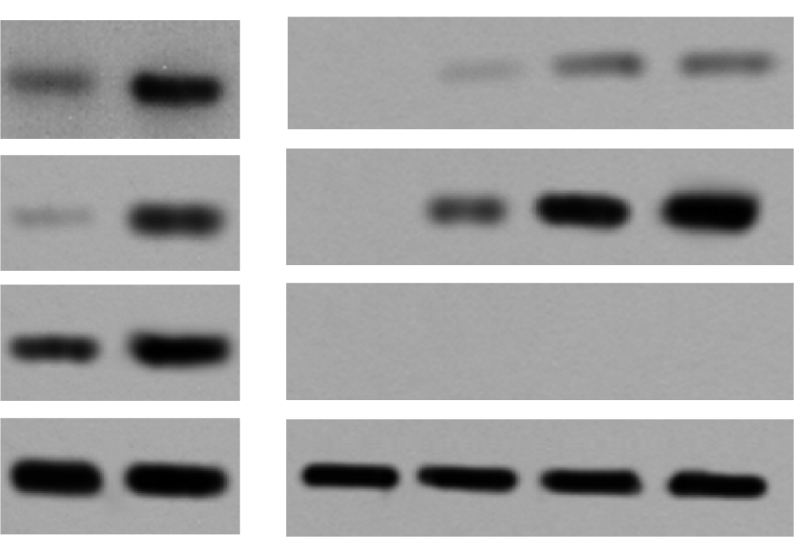

$\mathrm{D}$

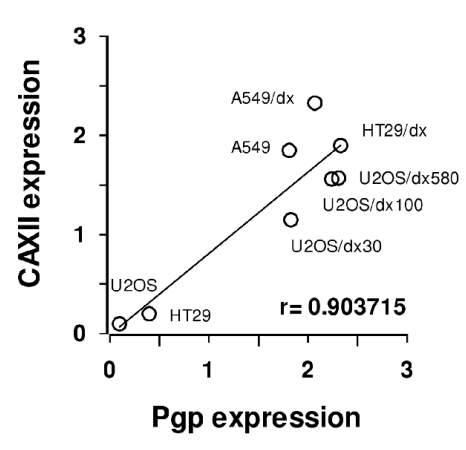

Figure 2: Expression of CAXII in chemosensitive and chemoresistant human cancer cells. Human chemosensitive colon cancer HT29 cells and their chemoresistant counterpart HT29/dx cells, human chemosensitive lung cancer A549 cells and their chemoresistant counterpart A549/dx cells, human chemosensitive osteosarcoma U2-OS cells and the chemoresistant clones U2-OS/dx 30, U2-OS/dx 100, U2-OS/dx 580 were subjected to the following assays. (A) Confocal microscope analysis of HT29 and HT29/dx cells stained for CAXII. The samples were analyzed by laser scanning confocal microscope for green fluorescence signal (CAXII) or by Nomarski differential interference contrast (DIC) optics. Magnification: $60 \times$ objective; $10 \times$ ocular lens. Bar $=20 \mu \mathrm{m}$. (B) Western blot analysis of biotinylated plasma membrane associated CAXII, Pgp and MRP1 in HT29 and HT29/dx cells. The pan-cadherin expression was used as a control of equal protein loading. The figure is representative of three experiments with similar results. (C) Whole cell lysates were analyzed by Western blotting for the expression of CAXII, Pgp and MRP1. The $\beta$-tubulin expression was used as a control of equal protein loading. The figure is representative of three experiments with similar results. (D) Linear regression analysis between CAXII and Pgp expression. The mean band density of CAXII and Pgp (panel C), expressed as arbitrary units, was calculated by ImageJ software (http:// www.rsb.info.nih.gov/ij/). r coefficient was calculated using Fig. P software (Fig. P Software Inc., Hamilton, Canada). 
A

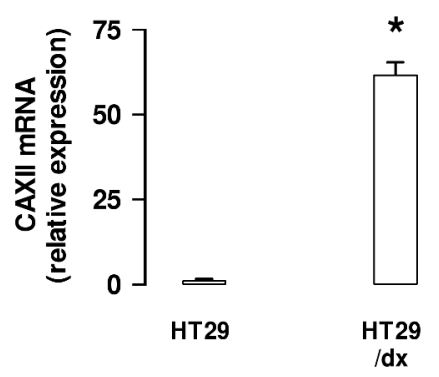

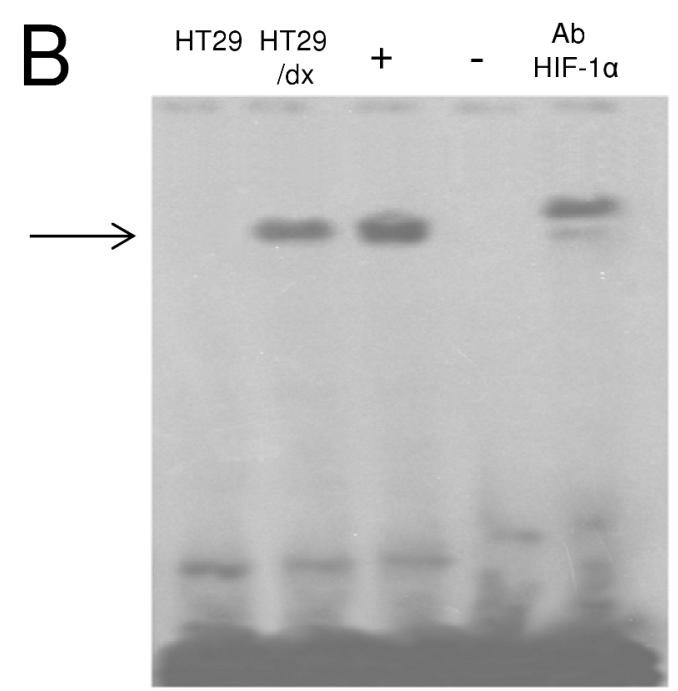

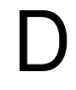

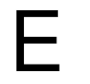
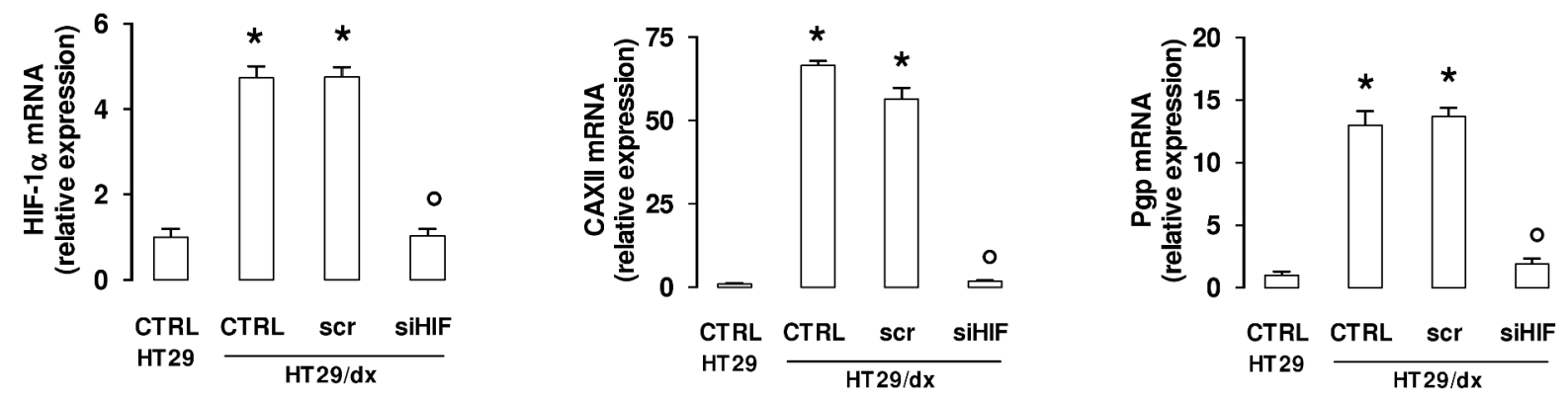

Figure 3: CAXII and Pgp expression levels are affected by HIF-1 $\alpha$ in chemoresistant cells. (A) The CAXII mRNA level in HT29 and HT29/dx cells was detected by qRT-PCR. Data are presented as means \pm SD $(n=4)$. Versus HT29: * $p<0.001$. (B) EMSA detection of HIF-1 $\alpha$ bound to its DNA consensus sequence was performed on nuclear extracts of normoxic HT29 and HT29/dx cells. Hypoxic HT29 cells (grown at 2\% $\mathrm{O}_{2}$ for $24 \mathrm{~h}$ ) were used as positive control of HIF-1 $\alpha$ activation $(+$ ). One lane was loaded with distilled water in place of cell extracts and was used as negative control (-). As control of specificity, the nuclear extracts of hypoxic HT29 cells were incubated with an anti-HIF-1 $\alpha$ antibody (Ab HIF-1 $\alpha$ ). The band corresponding to the HIF-1 $\alpha$-DNA complex is indicated by the arrow. The figure is representative of three experiments with similar results. (C-E) mRNA was extracted from wild-type HT29 cells and HT29/ dx cells (CTRL), HT29/dx cells treated with a non targeting scrambled siRNA (scr) or with a HIF-1 $\alpha$-targeting specific siRNA pool (siHIF) for $24 \mathrm{~h}$. The expression of HIF-1 $\alpha$ (panel C), CAXII (panel D) and Pgp (panel E) was detected by qRT-PCR. Data are presented as means $\pm \mathrm{SD}(n=4)$. Versus CTRL HT29: ${ }^{*} p<0.001$; versus CTRL HT29/dx: ${ }^{\circ} p<0.001$.

transcription factor hypoxia inducible factor- $1 \alpha(\mathrm{HIF}-1 \alpha)$ might be involved in the control of CAXII expression. HIF$1 \alpha$ activity was undetectable in HT29 cells, but present in HT29/dx where the protein was bound to HRE-containing DNA probes even under normoxic conditions (Figure 3B). In the chemoresistant cells, this leads to increased transcription of HIF-1 $\alpha$ target genes, such as glucose transporter 1, hexokinase, aldolase-A, glyceraldehyde 3-phosphate dehydrogenase, phosphoglycerate kinase, enolase-A, lactate dehydrogenase, vascular endothelial growth factor, erythropoietin in the chemoresistant cells (Supplemental Figure 6). Moreover, HT29/dx cells had significantly higher levels of $H I F-1 \alpha$ mRNA, together with increased levels of $C A X I I$ and $P g p$ mRNA, a known target gene of HIF-1 $\alpha$ [21], than HT29 cells
(Figure 3C-3E). Interestingly, HIF-1 $\alpha$ silencing in HT29/ $\mathrm{dx}$ cells (Figure $3 \mathrm{C}$ ) produced a strong reduction of both $C A X I I$ (Figure 3D) and Pgp mRNA (Figure 3E), without affecting cell proliferation, apoptosis and viability of these cells (not shown).

The selection of chemoresistant cells from parental chemosensitive HT29 cells with increasing concentrations of doxorubicin induced a progressive increase of $H I F-1 \alpha$ mRNA, measured every 5 passages of cell culture during the selection process (Figure 4A). The observed HIF-1 $\alpha$ increase was paralleled by the progressive increase in CAXII (Figure 4B) and $P g p$ (Figure $4 \mathrm{C}$ ) mRNA, and by the progressive decrease in the accumulation of doxorubicin (Figure 4D), a substrate of Pgp. 

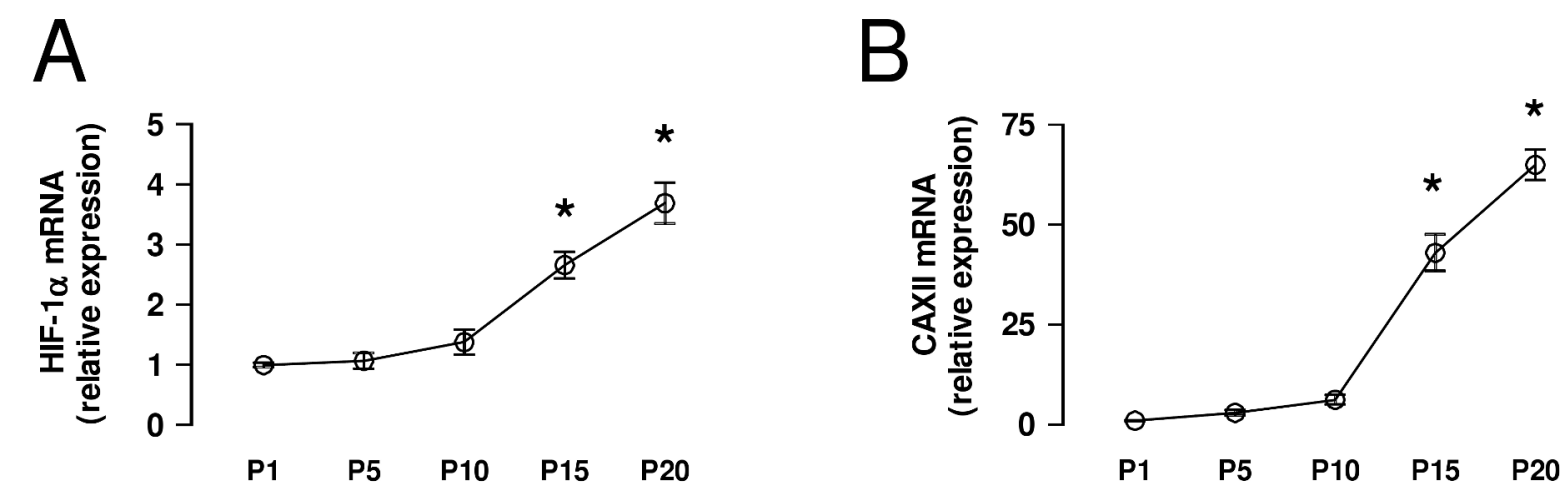

C
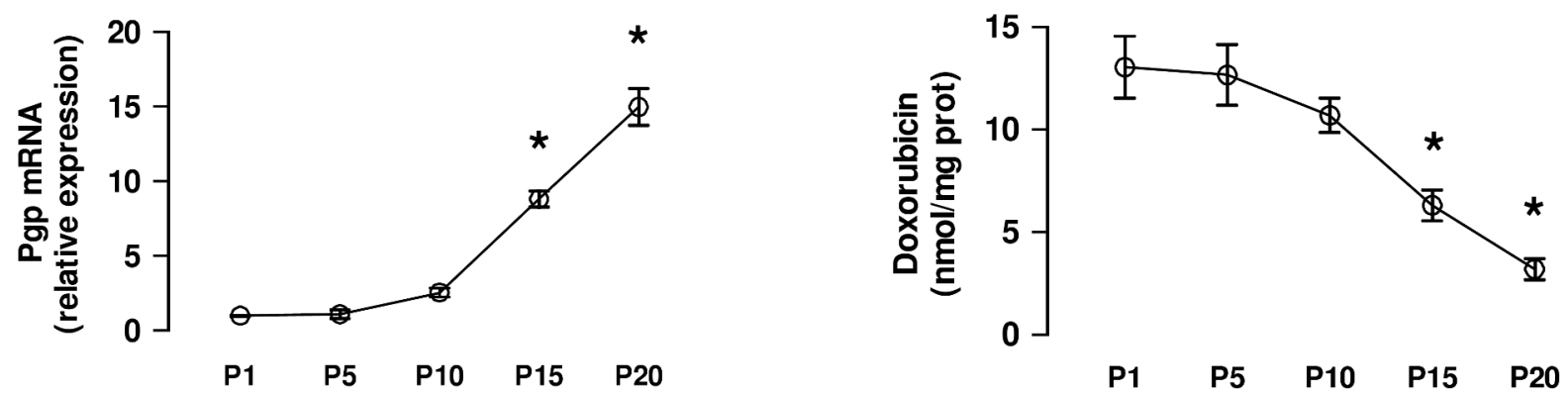

Figure 4: CAXII increases during the acquisition of chemoresistance. HT29 cells were cultured in medium containing increasing concentrations of doxorubicin, as detailed under Methods. (A-C) At passage $(P)$ 1, 5, 10, 15, 20 the mRNA was extracted and the expression of HIF-1 $\alpha$ (panel A), CAXII (panel B) and Pgp (panel C) was detected by qRT-PCR. Data are presented as means \pm SD $(n=4)$. Versus P1: ${ }^{*} p<0.001$. (D) An aliquot of cells was incubated $24 \mathrm{~h}$ with $5 \mu \mathrm{mol} / \mathrm{L}$ doxorubicin, then lysed and analyzed for the intracellular doxorubicin content. Data are presented as means $\pm \mathrm{SD}(n=4)$. Versus $\mathrm{P} 1{ }^{*} p<0.001$

\section{Depletion of CAXII does not affect proliferation and survival of chemoresistant cells}

To investigate the functional role of CAXII in chemoresistant cells, we produced a HT29/dx subclone silenced for CAXII (Figure 5A). HT29 and HT29/dx cells did not show any appreciable difference in terms of: cell proliferation, as revealed by the proportion of Ki67positive cells (Figure 5B); spontaneous apoptotic cell death, as indicated by the percentage of annexin V-fluorescein isothiocyanate (FITC)/propidium iodide (PI)-positive cells (Figure 5C); autophagy, as indicated by the expression level of classical autophagic markers such as beclin, ATG12 and LC3B (Figure 5D). Interestingly, untreated HT29/ $\mathrm{dx}$ cells appeared more senescent than parental HT29 cells, as suggested by higher staining with $\beta$-galactosidase (Figure 5E). Despite the documented role of CAXII as a prooncogenic factor [22], enzyme silencing did not alter any of these parameters in chemoresistant cells (Figure 5B-5E).

\section{CAXII is associated with Pgp and is necessary to maintain Pgp-mediated chemoresistance}

Confocal microscope analysis showed that CAXII and Pgp co-localized on HT29/dx cells plasma membrane (Figure 6A). In co-immunoprecipitation assays, we found that CAXII was physically associated with Pgp, but not with MRP1 on HT29/dx cells plasma membrane (Figure 6B). CAXII co-immunoprecipitated with both glycosylated and deglycosylated Pgp (Supplemental Figure 7A). In some cell lines deglycosylated Pgp is less active, but in HT29/dx the glycosylation status of Pgp did not affect its ATPase activity (Supplemental Figure 7B).

These observations raised the question whether CAXII directly affected the activity of Pgp. Supporting this hypothesis, CAXII silencing in HT29/dx cells led to a dramatic decrease in Pgp ATPase activity (Figure 6C). As expected, HT29/dx cells accumulated significantly less doxorubicin than HT29 cells. In contrast, CAXII-silenced HT29/dx cells showed significantly increased levels of intracellular doxorubicin, reaching the same amount measured in HT29 cells (Figure 6D), where Pgp was undetectable (Figure 2C). In keeping with the different expression levels of Pgp, chemotherapeutic drugs that are substrates of Pgp, such as doxorubicin and irinotecan [23], reduced cell viability of HT29 cells, but not HT29/dx cells. However, both doxorubicin and irinotecan exhibited cytotoxic effects on HT29/dx cells silenced for CAXII (Figure 6E). 


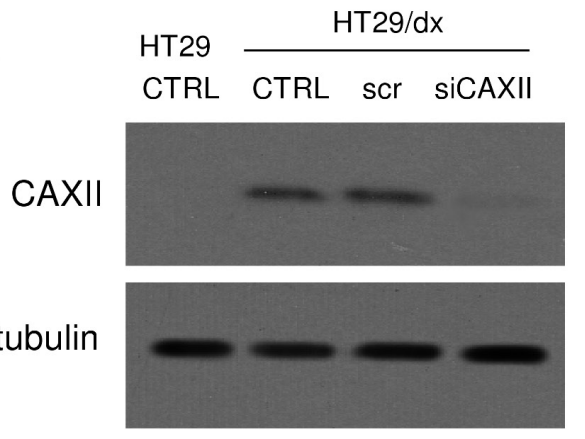

B
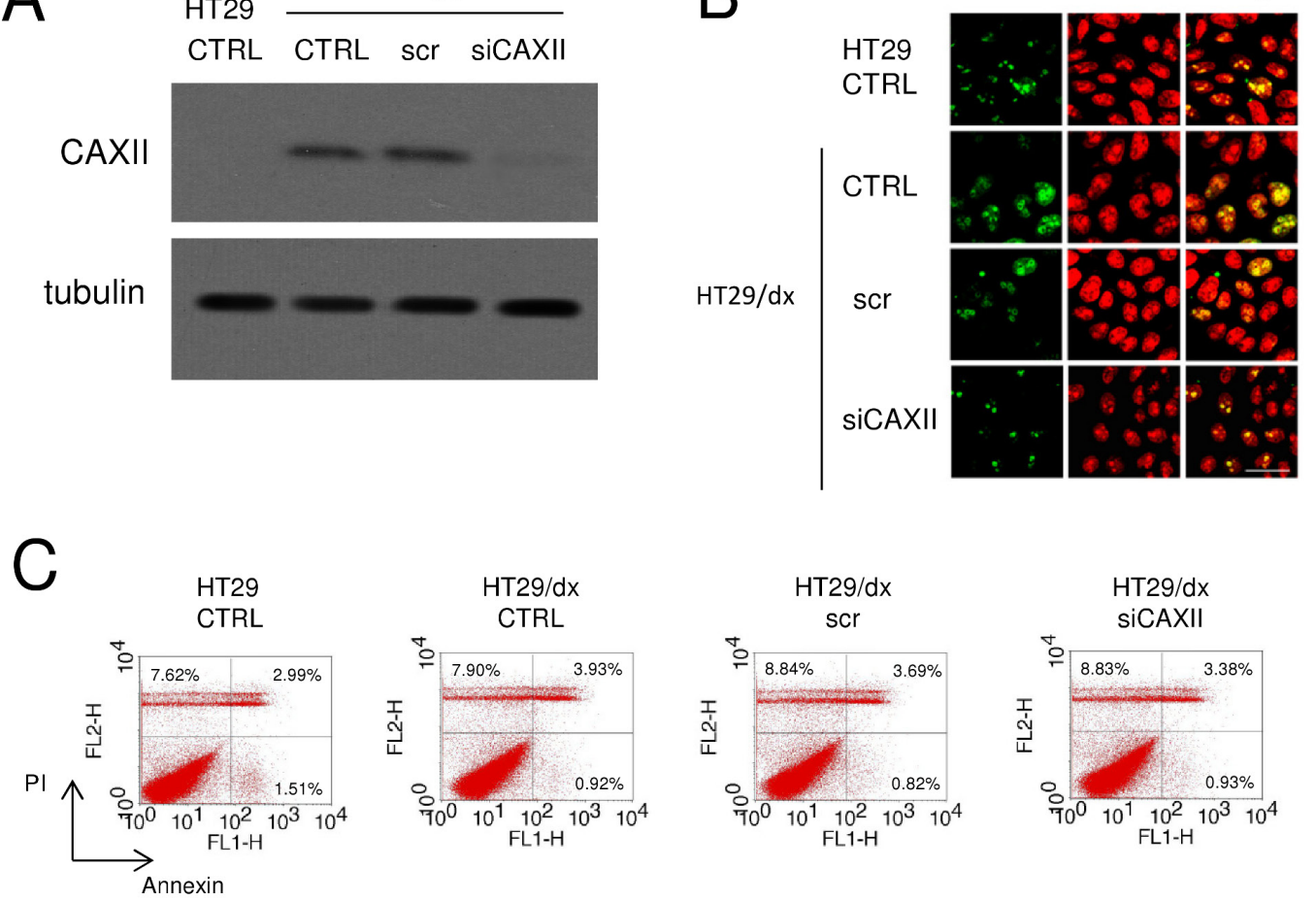

D

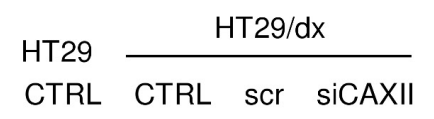

beclin

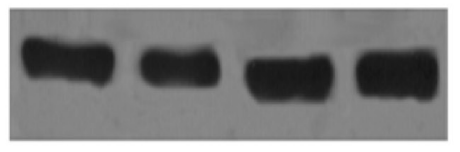

ATG12

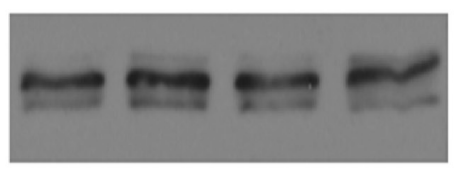

LC3B

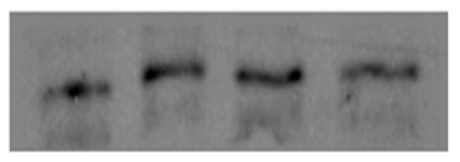

tubulin
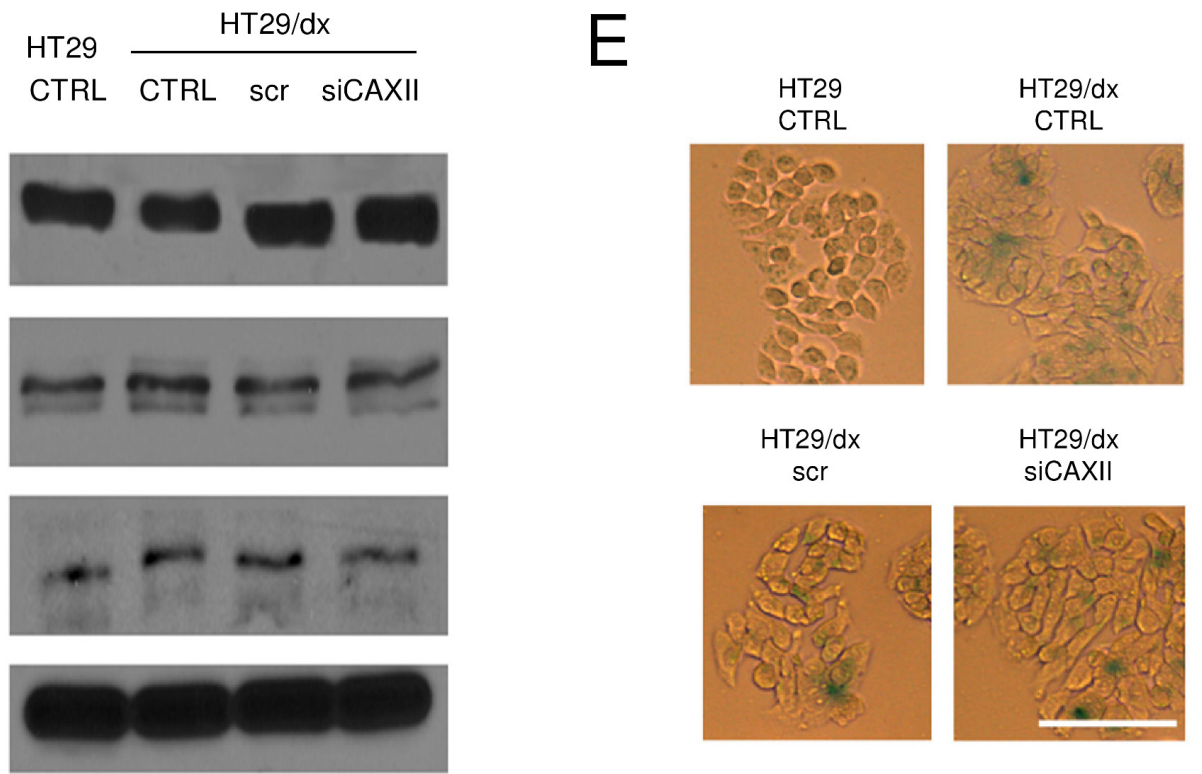

Figure 5: Depletion of CAXII does not affect proliferation and survival of chemoresistant cells. HT29/dx cells were cultured for $48 \mathrm{~h}$ with fresh medium (CTRL), treated with a non targeting scrambled siRNA (scr) or with a CAXII-targeting specific siRNA pool (siCAXII). HT29 cells were included as control. (A) The expression of CAXII was measured in whole cell lysates by Western blotting. The $\beta$-tubulin expression was used as a control of equal protein loading. The figure is representative of three experiments with similar results. (B) Confocal microscope analysis of cells stained for the proliferation marker Ki67. The samples were analyzed by laser scanning confocal microscopy for Ki67 protein signal (green fluorescence) or for PI (red fluorescence), used to visualize nuclei. Magnification: $60 \times$ objective; $10 \times$ ocular lens. Bar $=20 \mu \mathrm{m}$. (C) The percentage of cells positive to annexin V-FITC, as index of early apoptosis, and to PI, as index of late apoptosis, was measured by flow cytometry. Percentages indicate annexin V-positive cells (lower right quadrant), PI-positive cells (upper left quadrant), annexin V/PI-positive cells (upper right quadrant). The figures are representative of three experiments with similar results. (D) Western blot analysis of the autophagy markers beclin, ATG12 and LC3B. The $\beta$-tubulin expression was used as a control of equal protein loading. The figure is representative of three experiments with similar results. (E) Cells were fixed and stained for $\beta$-galactosidase activity, then examined by fluorescence microscopy. Magnification: $20 \times$ objective; $10 \times$ ocular lens. Bar $=100 \mu$ m. 

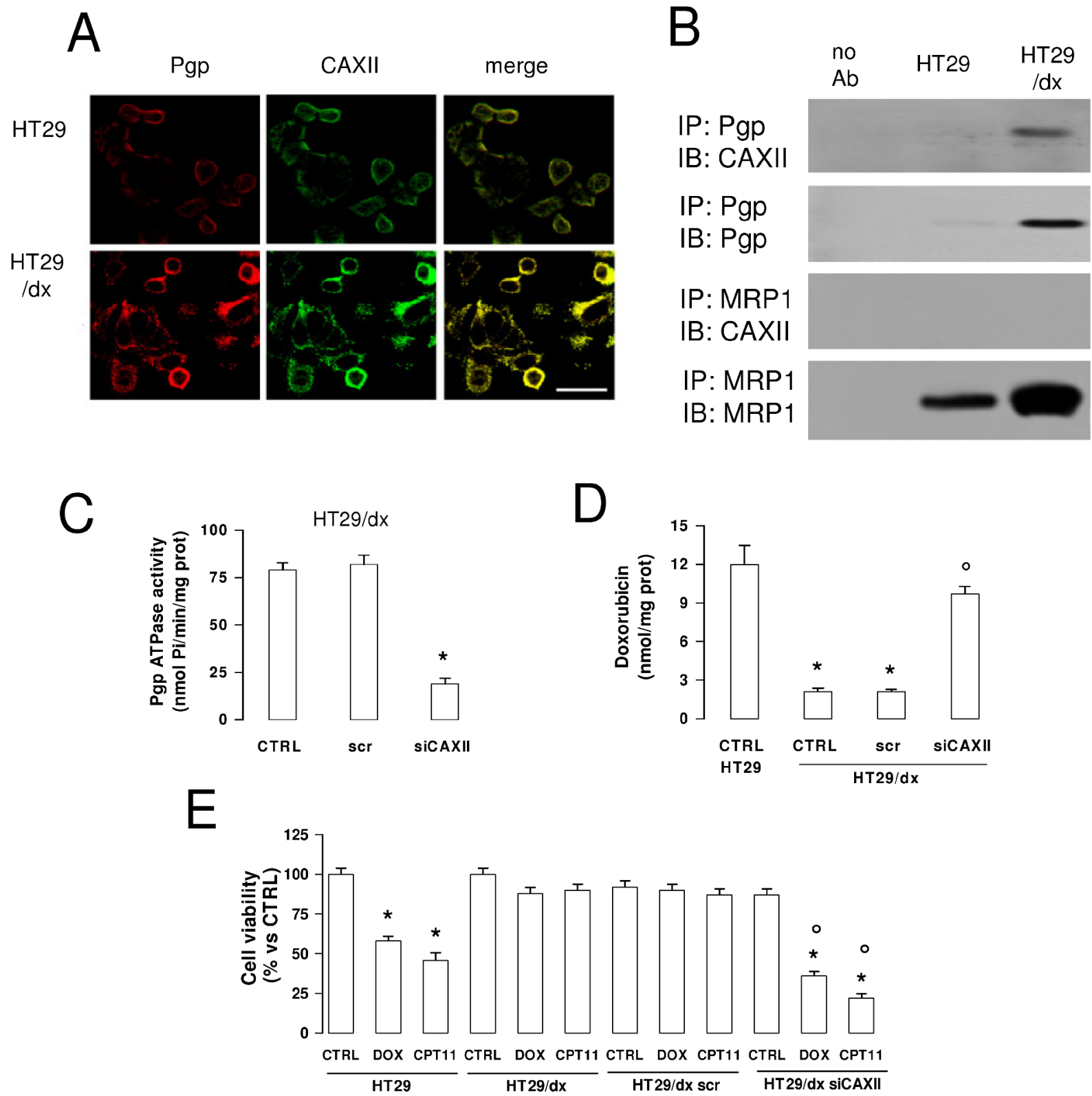

Figure 6: CAXII is physically associated with Pgp and increases Pgp activity in chemoresistant cells. (A) Confocal microscope analysis of HT29 and HT29/dx cells stained for CAXII and Pgp. The samples were analyzed by laser scanning confocal microscope for green (CAXII) or red (Pgp) fluorescence signal. Magnification: $60 \times$ objective; $10 \times$ ocular lens. Bar $=20 \mu \mathrm{m}$. $(\mathbf{B})$ Biotinylated plasma membrane-derived extracts from HT29 and HT29/dx cells were immunoprecipitated (IP) with anti-Pgp or antiMRP1 antibodies, then immunoblotted (IB) with anti-CAXII, anti-Pgp or anti-MRP1 antibodies. no Ab: samples immunoprecipitated without antibody. The figure is representative of three experiments with similar results. (C) HT29/dx cells were cultured for $48 \mathrm{~h}$ with fresh medium (CTRL), treated with a non targeting scrambled siRNA (scr) or with a CAXII-targeting specific siRNA pool (siCAXII). The Pgp ATPase activity was measured spectrophotometrically on Pgp-rich vesicles extracted from membrane fractions. Data are presented as means $\pm \mathrm{SD}(n=4)$. Versus CTRL: ${ }^{*} p<0.001$. (D) Cells treated as reported in C were incubated for $24 \mathrm{~h}$ with $5 \mu \mathrm{mol} / \mathrm{L}$ doxorubicin, then the intracellular drug content was measured fluorimetrically. HT29 were included as control of chemosensitive cells. Data are presented as means $\pm \mathrm{SD}(n=4)$. Versus HT29 CTRL: ${ }^{*} p<0.001$; versus HT29/dx CTRL: ${ }^{\circ} p<0.001$. (E) Cells treated as reported in $\mathrm{C}$ were grown for $72 \mathrm{~h}$ in fresh medium (CTRL), or in medium containing $5 \mu \mathrm{mol} / \mathrm{L}$ doxorubicin $(\mathrm{DOX})$ or $1 \mu \mathrm{M}$ irinotecan (CPT11), then stained with neutral red dye. The absorbance of viable cells was measured spectrophotometrically. Data are presented as means $\pm \mathrm{SD}(n=4)$. For HT29 and HT29/dx cells, versus CTRL: ${ }^{*} p<0.001$; for HT29/dx cells, versus wild type HT29/dx DOX or HT29/dx CPT11, respectively: ${ }^{\circ} p<0.002$. 

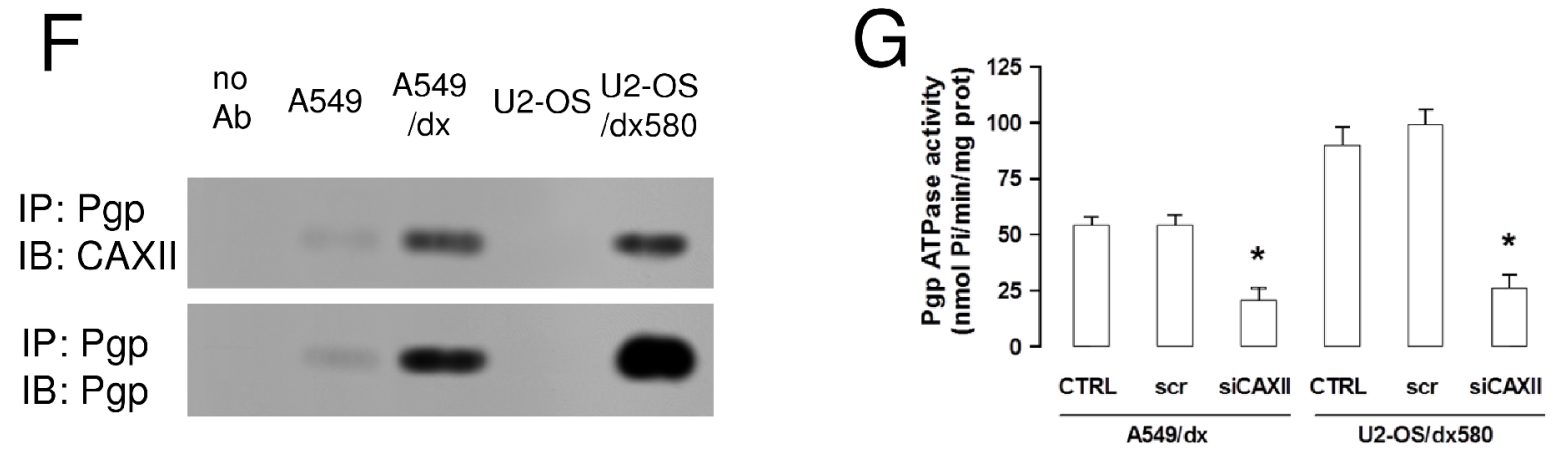

Figure 6: (Continued) (F) Biotinylated plasma membrane-derived extracts from human chemosensitive lung cancer A549 cell and chemoresistant A549/dx cells, human chemosensitive osteosarcoma U2-OS cells and chemoresistant U2-OS/dx580 cells were immunoprecipitated (IP) with an anti-Pgp antibody, then immunoblotted (IB) with an anti-CAXII or an anti-Pgp antibody. no Ab: samples immunoprecipitated without antibody. The figure is representative of two experiments with similar results. (G) A549/dx and U2-OS/dx580 cells were grown in fresh medium (CTRL), treated with a non targeting scrambled siRNA (scr) or with a CAXII-targeting specific siRNA pool (siCAXII). The Pgp ATPase activity was measured spectrophotometrically on Pgp-rich vesicles extracted from membrane fractions. Data are presented as means $\pm \mathrm{SD}(n=3)$. For both cell lines, versus CTRL: ${ }^{*} p<0.001$.

The association between Pgp and CAXII was shared by other chemoresistant cells, such as lung cancer A549/ $\mathrm{dx}$ cells and osteosarcoma resistant clones (Figure 6F). In analogy to HT29/dx cells, CAXII silencing (Supplemental Figure 8) reduced Pgp ATPase activity in these cell lines (Figure 6G).

CAIX is another isoform of carbonic anhydrase. This isoform is known to be highly expressed in tumors, including colon cancer, and has been linked to tumor aggressiveness and resistance to therapy [20]. This led us to investigate the expression levels of CAIX in our model system. In HT29 cells, CAIX mRNA levels were higher than the ones of CAXII, but were not increased in HT29/dx cells, where levels were significantly lower than for CAXII (Figure 7A). CAIX protein was detectable in HT29 and HT29/dx cells, without differences between chemosensitive and chemoresistant cells, both in whole cell lysates and in plasma membrane-derived extracts (Figure 7B). In contrast to CAXII (Figure 6B), CAIX did not co-immunoprecipitate with Pgp in plasma membrane extracts (Figure 7C). Moreover, CAIX-silenced HT29/ $\mathrm{dx}$ cells (Figure 7D) retained the same low amount of intracellular doxorubicin than wild-type HT29/dx cells (Figure 7E), suggesting that CAIX is not involved in the chemosensitization towards Pgp substrates.

\section{Pharmacological inhibition of CAXII restores chemosensitivity in chemoresistant cancer cells}

Similarly to the effect of CAXII silencing, the CAXII inhibitor acetazolamide (Ki $5.6 \pm 0.2 \mathrm{nM}$ ) [24] dose-dependently reduced the activity of Pgp (Figure $8 \mathrm{~A}$ ), suggesting that the activity of CAXII is critical for the catalytic activity of the transporter. At $1 \mu \mathrm{mol} / \mathrm{L}$, acetazolamide, which was devoid of effects in HT29 cells where CAXII and Pgp were hardly detectable by Western blot (Figure 2B-2C), significantly increased the retention of doxorubicin (Figure $8 \mathrm{~B}$ ) and restored the cytotoxic effects of doxorubicin and irinotecan in HT29/dx cells (Figure 8C).

The activity of CAIX and CAXII has been reported to induce intracellular alkalinization [25]. As shown in Figure $8 \mathrm{D}$, the $\mathrm{pH}_{\mathrm{i}}$ of HT29 was $7.39 \pm 0.02$, whereas the $\mathrm{pHi}$ of HT29/dx was $7.58 \pm 0.03$. To investigate whether CAXII contributes to this different $\mathrm{pHi}$ between chemosensitive and chemoresistant cells, we measured the pHi in HT29/dx cells silenced for CAXII or treated with acetazolamide: interestingly, these experimental conditions lowered the $\mathrm{pH}_{\mathrm{i}}$ of HT29/dx cells to values similar to HT29 cells. By contrast, acetazolamide did not affect the $\mathrm{pH}_{\mathrm{i}}$ of low CAXII-expressing HT29 cells (Figure 8D). To evaluate whether such different $\mathrm{pHi}$ conditions may affect the activity of Pgp, we measured the ATPase activity of Pgp from HT29/dx plasma membrane in buffers with different $\mathrm{pH}$. We did not detect changes in the basal ATPase activity of Pgp; by contrast, the verapamil-stimulated ATPase activity of Pgp, taken as an index of the transporter's maximal activity, increased from $\mathrm{pH} 7.0$ to $\mathrm{pH} 7.6$ (Figure 8E), suggesting that the optimal $\mathrm{pH}$ at which Pgp operates is slightly alkaline (i.e. compatible with the $\mathrm{pH}_{\mathrm{i}}$ of HT29/dx cells) and that the $\mathrm{pH}$ produced by CAXII inhibition likely lowered Pgp activity.

\section{DISCUSSION}

In this work we analyzed the surfaceome of chemosensitive Pgp-negative and chemoresistant Pgppositive human colon cancer cells and identified CAXII more highly expressed in the latter.

CAXII is a surface-associated enzyme highly expressed in tumors of renal [26], ovarian [27] and colorectal [28] origin, where it maintains the homeostasis of $\mathrm{HCO}_{3}^{-}$[29]. 


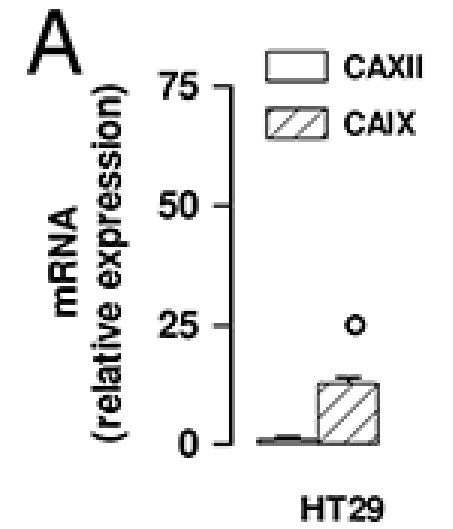

B

Total

CAIX

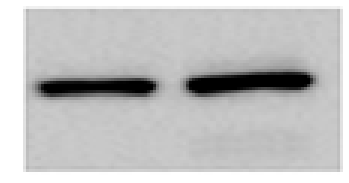

tubulin

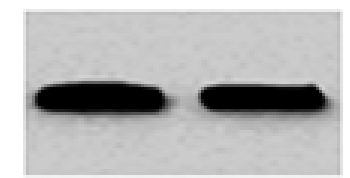

Surface

pan-cadherin
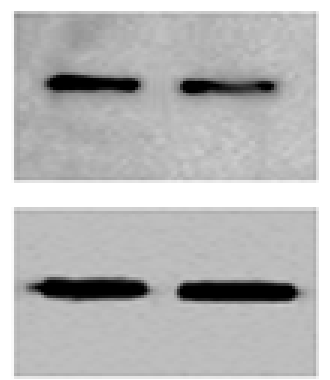

C

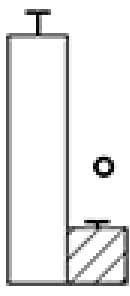

HT29

/dx

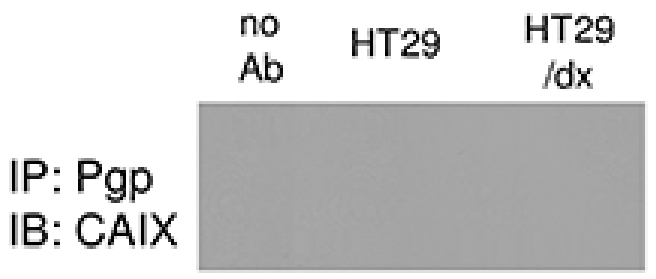

IP: Pgp

IB: Pgp

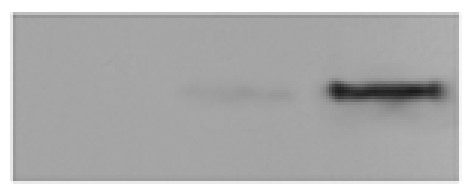

D

CAIX

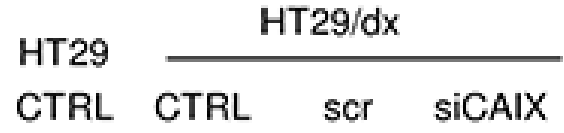

tubulin
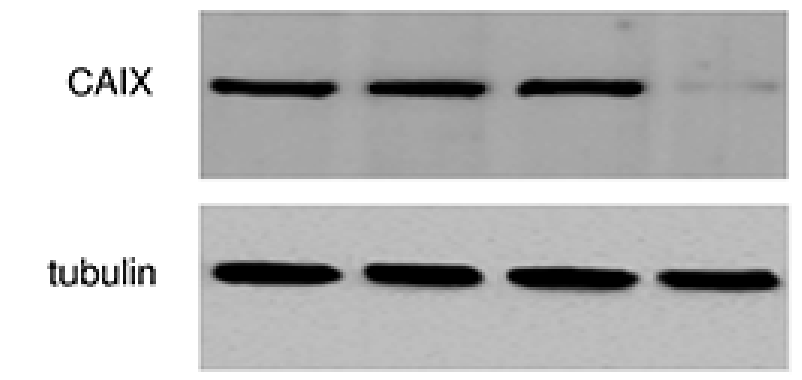

E

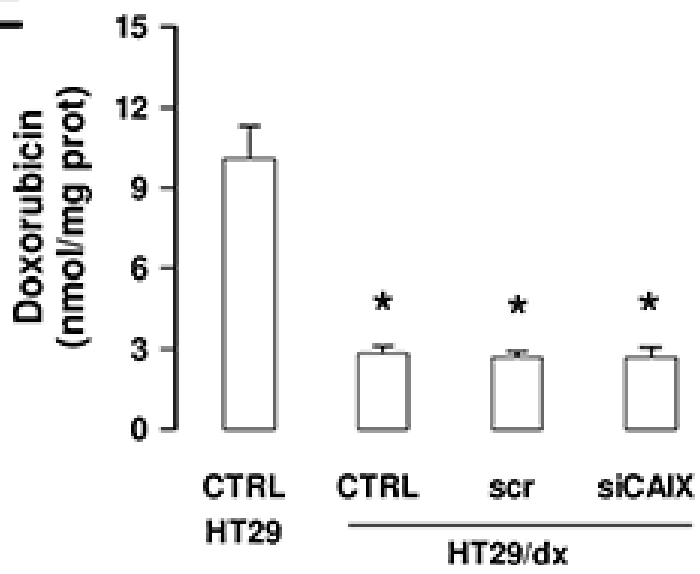

Figure 7: CAIX does not mediate chemoresistance to Pgp substrates in colon cancer cells. (A) The $C A I X$ mRNA level in HT29 and HT29/dx cells was detected by qRT-PCR. CAXII mRNA level is shown for comparison. Data are presented as means \pm SD $(n=4)$. Versus HT29: $* p<0.001$; for both HT29 and HT29/dx cells, CAIX versus CAXII expression: ${ }^{\circ} p<0.001$. (B) Western blot analysis of CAIX expression in whole cell lysates (upper panel; Total) and biotinylated plasma membrane-derived extracts (lower panel; Surface) in HT29 and HT29/dx cells. The $\beta$-tubulin and pan-cadherin expression were used as controls of equal protein loading in whole cell lysates and plasma membrane-derived extracts, respectively. The figure is representative of three experiments with similar results. (C) Biotinylated plasma membrane-derived extracts from HT29 and HT29/dx cells were immunoprecipitated (IP) with an anti-Pgp antibody, then immunoblotted (IB) with an anti-CAIX or an anti-Pgp antibody. no Ab: samples immunoprecipitated without antibody. The figure is representative of three experiments with similar results. (D) HT29/dx cells were cultured for $48 \mathrm{~h}$ with fresh medium (CTRL), treated with a non targeting scrambled siRNA (scr) or with a CAIX-targeting specific siRNA pool (siCAIX). HT29 cells were included as control. The expression of CAIX was measured in whole cell lysates by Western blotting. The $\beta$-tubulin expression was used as a control of equal protein loading. The figure is representative of three experiments with similar results. (E) HT29/dx cells treated as reported in D were incubated for $24 \mathrm{~h}$ with $5 \mu \mathrm{mol} / \mathrm{L}$ doxorubicin, then the intracellular drug content was measured fluorimetrically. HT29 cells were included as control of chemosensitive cells. Data are presented as means $\pm \operatorname{SD}(n=4)$. Versus HT29 CTRL: $* p<0.001$. 


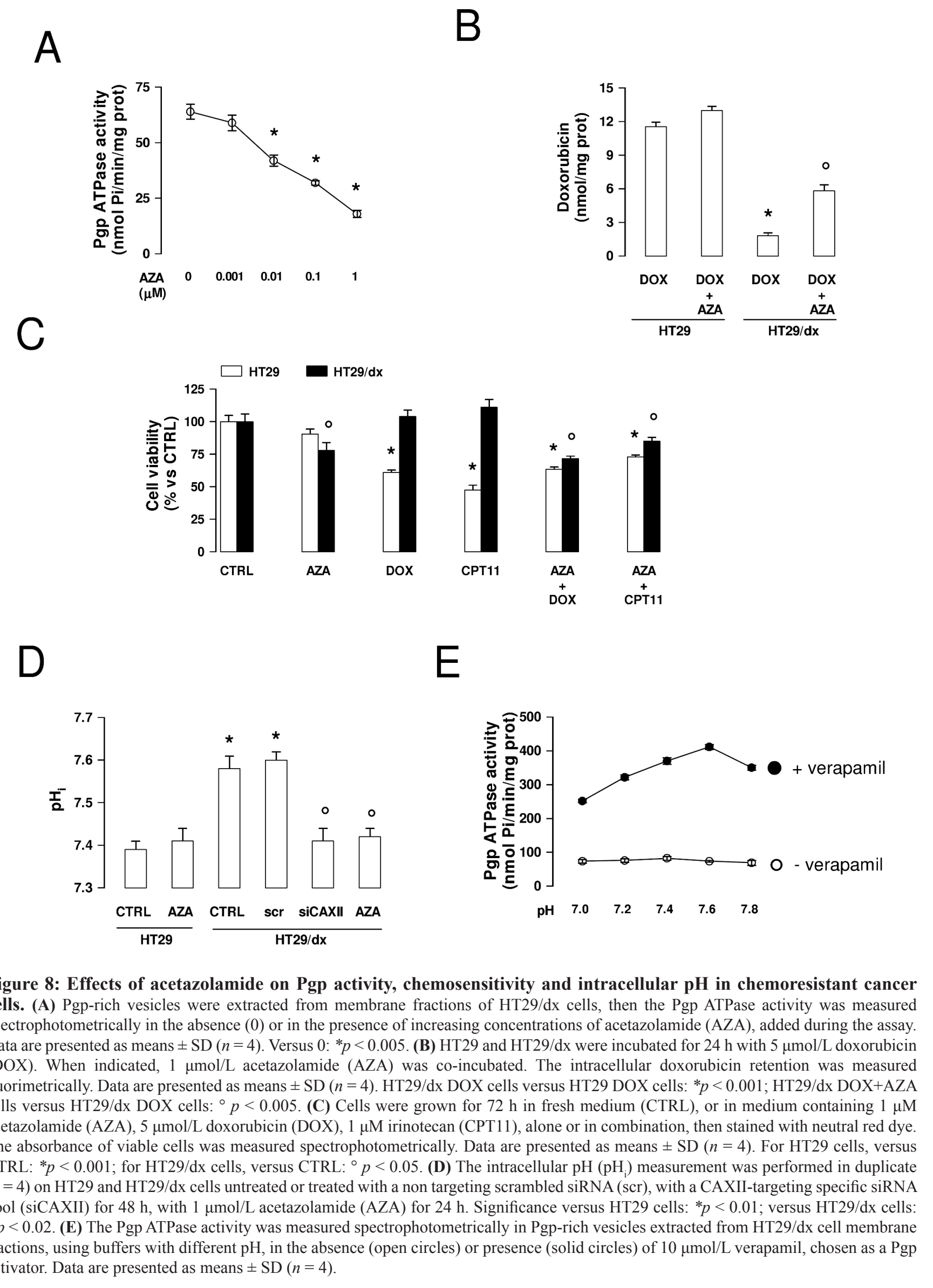


In our model of chemoresistant colon cancer cells, CAXII was increased at both the protein and mRNA level, suggesting that $C A X I I$ gene transcription was upregulated. The presence of HRE sequences in upstream regions of the $C A X I I$ gene, and the down-regulation of $C A X I I$ mRNA in cells expressing the Von Hippel Lindau protein, a HIF-1 $\alpha$-inhibitor [20], led us to the hypothesis that HIF-1 $\alpha$ might be involved in the control of CAXII expression. In HT29/dx cells, HIF-1 $\alpha$ was constitutively active even under normoxia, as demonstrated by its constitutive binding of hypoxia-responsive DNA elements, and by higher expression levels of its classical target genes. This characteristic was progressively acquired during the selection of resistant clones from the parental chemosensitive population exposed to doxorubicin. Although we have previously reported the constitutive activation of HIF-1 $\alpha$ in normoxic cancer cells with a stable MDR phenotype [30], the parallel increase in HIF$1 \alpha$ transcription and the progressive acquisition of MDR is a new observation. This trend may be due to the use of doxorubicin as selective agent: indeed, in normoxia the drug produces reactive oxygen species [31] that increase HIF-1 $\alpha$ [32]. During the onset of the MDR phenotype, the increase of HIF-1 $\alpha$ was paralleled by an increase of CAXII and Pgp mRNAs. These data suggest that HIF-1 $\alpha$ may play a role in the up-regulation of CAXII in HT29/ $\mathrm{dx}$ cells. Since the relative increase of $C A X I I \mathrm{mRNA}$ was greater than for classical target genes of HIF-1 $\alpha$, other transcription factors and co-activators induced during the selection of chemoresistant clones - in addition to HIF$1 \alpha-$ are likely to be involved in the up-regulation of the CAXII gene.

In previous reports, CAXII overexpression has been associated with good $[33,34]$ or poor $[35,36]$ prognosis, depending on the tumor type. Furthermore, the protein has been reported to support cell proliferation and invasion, based on the observations that a monoclonal antibody against CAXII reduced tumor growth [22] and that CAXII inhibitors lowered metastatic potential [37] in mouse xenografts. However, according to the results obtained by CAXII silencing in HT29/dx cells, CAXII did not confer any selective advantage in terms of cell proliferation, spontaneous necrotic/apoptotic death, autophagy or senescence rate. By contrast, we found that CAXII promoted the acquisition and maintenance of chemoresistance.

In our study, Pgp and MRP1 were found to be up-regulated on the plasma membrane of HT29/dx cells. Whereas CSC technology successfully identified MRP1, it failed to identify Pgp. The gel shift of the MRP1 band upon treatment with Peptide-N-Glycosidase F (PNGase F) was bigger than the gel shift of the Pgp band, suggesting that the extent of glycosylation was higher in MRP1. This makes MRP1 easier to detect by CSC, which specifically identifies N-glycopeptides of cell surface proteins. Moreover, Pgp was highly abundant in its deglycosylated form in HT29/dx cells. Of note, CAXII was physically associated with both glycosylated and deglycosylated Pgp, which were equally active. We did not further investigate which domain of CAXII may be responsible for the interaction with Pgp. Pgp has a large intracellular domain (Supplemental Figure 9) and according to the crystal structure of CAXII, the intracellular C-terminal domain of the enzyme is likely to be responsible for the interactions with other proteins, the oligomerization of CAXII, the catalytic activity and the signal transduction [38].

In all chemoresistant cells tested in this study, CAXII appeared to support Pgp activity: CAXII-silenced cells showed a decreased ATPase activity of Pgp, an increased retention of the Pgp substrate doxorubicin, and a restored cytotoxicity of doxorubicin and irinotecan.

However, we cannot exclude that other tumorassociated CA isoforms are involved in the onset or maintenance of chemoresistance. For instance, the overexpression of CAIX has been correlated with a low response to doxorubicin treatment in breast cancer patients [39]. In our model, CAIX was expressed at similar levels in HT29 and HT29/dx cells. Furthermore, it seemed to play a minor role in the resistance to doxorubicin as illustrated by the fact that CAIX-silenced HT29/dx cells had the same low intracellular retention of doxorubicin than wild-type HT29/dx cells. What about the resistance phenotype?

It has previously been reported that the verapamilstimulated activity of Pgp, considered an index of the maximal activity of the transporter, increases at slightly alkaline $\mathrm{pH}$ [40]. We confirmed this trend in Pgp-rich vesicles extracted from HT29/dx cells. The $\mathrm{pH}_{\mathrm{i}}$ measured in HT29/dx cells was lowered by CAXII silencing or by pharmacological CAXII inhibition with acetazolamide, suggesting that CAXII may contribute to maintain the slightly alkaline $\mathrm{pH}_{\mathrm{i}}$ of chemoresistant cells. A slightly alkaline $\mathrm{pHi}$ has been shown to induce resistance to doxorubicin in HT29/dx cells [41]. Furthermore, it has been reported that the activity of both CAIX and CAXII regulate the $\mathrm{pHi}$ homeostasis in cancer cells [25]. In our experiments, the selective silencing of CAIX and CAXII in HT29/dx cells suggested that only the latter was involved in the maintenance of doxorubicin resistance in this model. Since CAIX did not physically interact with Pgp, we hypothesize that it did not produce a sufficient alkalinization to reduce the transporter's efflux activity in the plasma membrane area where Pgp is localized. By contrast, the co-localization of Pgp and CAXII may favor the optimal $\mathrm{pH}$ condition for Pgp activity in the microenvironment where Pgp and CAXII are concentrated.

Our work shows that pharmacological inhibition of CAXII with acetazolamide effectively sensitizes resistant cells to the cytotoxic effects of Pgp substrates. 
Acetazolamide has antitumor activity in vivo [42] and increases doxorubicin cytotoxicity in HT29 cells under hypoxia [43].

Since acetazolamide is being used in clinical practice as a diuretic, our work - although based on in vitro experiments - may have translational potential in the future. Given the role of CAXII in tumor growth and invasion, selective inhibitors of CAXII are under active development as new anticancer drugs [44-46], in particular against hypoxic tumors [47]. We propose that these synthetic and more selective inhibitors might be used as chemosensitizing agents for the treatment of Pgp overexpressing tumors. To achieve a more selective targeting of tumor cells, liposome- or nanoparticle-based carriers, which increase the intratumor accumulation of drugs, either by passive targeting (i.e. by the enhanced permeability retention effect) or active targeting [48], represent a valid approach. Our proteomic screening showed that, besides CAXII, a considerable number of other surface antigens were expressed at significantly higher levels in MDR cells. Some of these proteins may represent suitable targets for liposomes carrying CAXII inhibitors for the active and more selective targeting of chemoresistant colon cancer cells in preclinical models.

In summary, we show for the first time that CAXII is more highly abundant at the plasma membrane of Pgppositive chemoresistant cells and is increased in parallel with Pgp during the acquisition of chemoresistance. Since CAXII activity is necessary for the optimal activity of Pgp, CAXII inhibitors may represent promising therapeutic tools to overcome Pgp-mediated chemoresistance.

\section{METHODS}

\section{Chemicals}

The plasticware for cell cultures was obtained from Falcon (Becton Dickinson, Franklin Lakes, NJ). The electrophoresis reagents were obtained from BioRad Laboratories (Hercules, CA). The protein content of cell lysates was assessed with the BCA kit from Sigma Chemicals Co. (St. Louis, MO). Unless specified otherwise, all reagents were purchased from Sigma Chemicals Co.

\section{Cells}

Human chemosensitive colon cancer HT29 cells (from ATCC, Manassas, VA) were cultured in RPMI 1640 medium. A subpopulation, called HT29/dx, was created by culturing parental cells with $12.5 \mathrm{nmol} / \mathrm{L}$ doxorubicin for passages $1-5,25 \mathrm{nmol} / \mathrm{L}$ doxorubicin for passages $6-10,50 \mathrm{nmol} / \mathrm{L}$ doxorubicin for passages $11-15,100$ $\mathrm{nmol} / \mathrm{L}$ doxorubicin for passages 16-20, then stably maintaining cells in RPMI 1640 medium containing 200 $\mathrm{nmol} / \mathrm{L}$ doxorubicin. HT29-dx cells displayed a higher abundance of Pgp, MRP1 and BCRP, and were crossresistant to doxorubicin and irinotecan [49]. Human chemosensitive lung cancer A549 cells (ATCC) and the chemoresistant A549/dx cell subline were obtained and cultured as reported [50]. Human doxorubicin sensitive osteosarcoma U2-OS cells and the corresponding clones with increasing resistance to doxorubicin (U2-OS/dx 30, U2-OS/dx 100, U2-OS/dx 580), selected by culturing U2-OS cells in a medium with $30,100,580 \mathrm{ng} / \mathrm{mL}$ doxorubicin, were a kind gift from Dr. Massimo Serra, Laboratory of Experimental Oncology (IRCCS Istituto Ortopedico Rizzoli, Bologna, Italy), and have been previously characterized [51].

\section{Surface glycoprotein identification via CSC technology}

Cells were prepared for CSC as described elsewhere [52]. Briefly, cells were treated for $15 \mathrm{~min}$ at $4^{\circ} \mathrm{C}$ in the dark with $2 \mathrm{mmol} / \mathrm{L}$ sodium meta-periodate (Thermo Fisher Scientific Inc., Waltham, MA) in PBS, $\mathrm{pH} 6.5$, then washed and incubated with $6.5 \mathrm{mmol} / \mathrm{L}$ biocytin hydrazide (Biotium, Hayward, CA) in PBS, $\mathrm{pH}$ 6.5, for $1 \mathrm{~h}$ to biotinylate oxidized carbohydrates of cell surface glycoproteins. Cells were washed, incubated on ice in hypotonic lysis buffer $(10 \mathrm{mmol} / \mathrm{L}$ Tris, $0.5 \mathrm{mmol} / \mathrm{L} \mathrm{MgCl}, 10 \mathrm{mmol} / \mathrm{L}$ iodoacetamide, $\mathrm{pH}$ 7.5) for $10 \mathrm{~min}$, homogenized for $10 \mathrm{~s}$ using a Dounce homogenizer. Afterward cell debris and nuclei were removed by centrifugation at $1700 \mathrm{x}$ g for 7 min. The supernatant was solubilized in $400 \mu \mathrm{L}$ of digestion buffer $\left(100 \mathrm{mmol} / \mathrm{L} \mathrm{NH}_{4} \mathrm{HCO}_{3}, 1 \mathrm{mmol} / \mathrm{L}\right.$ iodoacetamide, $1 \mathrm{mmol} / \mathrm{L} 2,2^{\prime}$-thiodiethanol, $0.1 \% \mathrm{w} / \mathrm{v}$ RapiGest; Waters, Milan, Italy) and sonicated with a VialTweeter instrument (Hielscher Ultrasonic $\mathrm{GmbH}$, Teltow, Germany). Proteins were digested overnight with trypsin in a protease:protein ratio of 1:100. After protein digestion, the peptide mixture was heated at $95^{\circ} \mathrm{C}$ for 10 $\mathrm{min}$ to inactivate trypsin, then biotinylated glycopeptides were bound to Streptavidin Plus UltraLink Resin (SA beads; Pierce, Rockford, IL) for $3 \mathrm{~h}$ at $37^{\circ} \mathrm{C}$. After extensive washing, cysteine containing peptides, which were bound via a disulfide bridge to the biotinylated glycopeptides, were eluted from the SA beads by incubation with elution buffer $\left(100 \mathrm{mmol} / \mathrm{L} \mathrm{NH}_{4} \mathrm{HCO}_{3}\right.$, $10 \mathrm{mmol} / \mathrm{L}$ tris(2-carboxyethyl)phosphine, $1 \mathrm{mmol} / \mathrm{L}$ dithiothreitol) for $1 \mathrm{~h}$ at room temperature. SA beads were washed again and N-linked glycopeptides were enzymatically released from the SA beads in a second overnight elution step in the presence of PNGase F. The free thiols of cysteine containing peptides were alkylated with iodoacetamide. Peptides were desalted on Ultra MicroTIP Columns (The Nest Group, Southborough, MA) and dried in a SpeedVac concentrator. Finally, peptides were solubilized in LC-MS grade water containing $0.1 \% \mathrm{v} / \mathrm{v}$ formic acid and $5 \% \mathrm{v} / \mathrm{v}$ acetonitrile. 
MS/MS spectra were acquired with a LTQ Orbitrap XL mass spectrometer, converted to mzXML and searched against the UniProt database (Version 57.15) using the SEQUEST algorithm. Statistical data analysis was performed using a combination of ISB (Institute of Systems Biology, Seattle, WA) open-source software tools (PeptideProphetTM, ProteinProphetTM, TPP Version 4.3.1). A ProteinProphet probability score of at least 0.9 was used for data-filtering (corresponding to a false discovery rate of $1 \%$ ). The protein functional classification was performed using the PANTHER algorithm (http://www.pantherdb.org). Quantitative data analysis was performed using the XPRESS software.

\section{Western blot analysis}

For whole cell lysates, the cells were rinsed with ice-cold lysis buffer $(50 \mathrm{mmol} / \mathrm{L}$ Tris, $10 \mathrm{mmol} / \mathrm{L}$ EDTA, 1\% v/v Triton-X100), supplemented with the protease inhibitor cocktail set III $(80 \mu \mathrm{mol} / \mathrm{L}$ aprotinin, $5 \mathrm{mmol} / \mathrm{L}$ bestatin, $1.5 \mathrm{mmol} / \mathrm{L}$ leupeptin, $1 \mathrm{mmol} / \mathrm{L}$ pepstatin; Calbiochem, San Diego, CA), $2 \mathrm{mmol} / \mathrm{L}$ phenylmethylsulfonyl fluoride and $1 \mathrm{mmol} / \mathrm{L} \mathrm{Na}_{3} \mathrm{VO}_{4}$, then sonicated and centrifuged at $13000 \mathrm{xg}$ for $10 \mathrm{~min}$ at $4^{\circ} \mathrm{C} .20 \mu \mathrm{g}$ protein extracts were subjected to SDS-PAGE and probed with the following antibodies: anti-CAXII (Abcam, Cambridge, UK); anti-CAIX (Novus Biologicals, Littleton, CO); anti-Pgp (C219, Calbiochem); anti-MRP1 (Abcam); anti-beclin (Abcam); anti-ATG12 (Abcam); antiLC3B (Abcam); anti- $\beta$-tubulin (Santa Cruz Biotechnology Inc., Santa Cruz, CA), followed by a peroxidaseconjugated secondary antibody (Bio-Rad Laboratories). The membranes were washed with Tris-buffered salineTween $0.1 \% \mathrm{v} / \mathrm{v}$, and the proteins were detected by enhanced chemiluminescence (Bio-Rad Laboratories). Plasma membrane-associated CAXII was evaluated in biotinylation assays, using the Cell Surface Protein isolation kit (Thermo Fisher Scientific Inc.), as previously reported [53], using an anti pan-cadherin antibody (Santa Cruz Biotechnology Inc.) to check the equal protein loading. In co-immunoprecipitation experiments, $100 \mu \mathrm{g}$ of proteins were immunoprecipitated with the anti-Pgp or anti-MRP1 antibodies, using the PureProteome protein A and protein G Magnetic Beads (Millipore, Billerica, MA). The immunoprecipitated proteins were separated by SDSPAGE and probed with the anti-CAXII, anti-CAIX, antiPgp or anti-MRP1 antibodies, followed by a peroxidaseconjugated secondary antibody. To detect glycosylated and deglycosyated proteins, biotinylated extracts (100 $\mu \mathrm{g}$ ) were heated at $99^{\circ} \mathrm{C}$ for $10 \mathrm{~min}$ to denature proteins, then incubated for $1 \mathrm{~h}$ at $37^{\circ} \mathrm{C}$ in the absence or presence of $1 \mu \mathrm{U}$ of human recombinant PNGaseF. Samples were resolved by SDS-PAGE and probed with the following antibodies, recognizing both the glycosylated and the deglycosylated forms: anti-Pgp (3C3.2, Millipore); antiMRP1 (Enzo Life Sciences, Farmingdale, NY).

\section{Confocal microscopy analysis}

$5 \times 10^{5}$ cells were grown on sterile glass coverslips, rinsed and fixed with $4 \% \mathrm{w} / \mathrm{v}$ paraformaldehyde for 15 min. To visualize surface CAXII and Pgp, the samples were washed with PBS and stained with an antiCAXII antibody or an anti-Pgp antibody conjugated to phycoerythrin (Millipore) for $1 \mathrm{~h}$. After washing, samples stained for CAXII were incubated with an AlexaFluor 488-conjugated secondary antibody (Millipore) for $1 \mathrm{~h}$ and re-washed. The coverslips were mounted with $4 \mu \mathrm{L}$ of Gel Mount Aqueous Mounting and examined with an Olympus FV300 laser scanning confocal microscope (Olympus Biosystems, Tokyo, Japan). For each experimental point, a minimum of five microscopic fields were examined.

\section{Quantitative real time-PCR (qRT-PCR)}

Total RNA was extracted and reverse-transcribed using the QuantiTect Reverse Transcription Kit (Qiagen, Hilden, Germany). The qRT-PCR was performed with the $\mathrm{IQ}^{\mathrm{TM}}$ SYBR Green Supermix (Bio-Rad Laboratories). The same cDNA preparation was used to quantify the genes of interest and the housekeeping gene S14. The primer sequences, designed using the qPrimerDepot database (http://primerdepot.nci.nih.gov/), are reported in the Supplemental Table 2. The relative quantification was performed by comparing each PCR product with the housekeeping PCR product, using the Bio-Rad Software Gene Expression Quantitation (Bio-Rad Laboratories).

\section{Electrophoretic mobility shift assay (EMSA)}

Nuclear extracts were prepared as previously reported [54]. The probe containing the HIF- $1 \alpha$ oligonucleotide consensus sequence was labeled with $\left[\gamma-{ }^{32} \mathrm{P}\right]-\mathrm{ATP}(3,000$ $\mathrm{Ci} / \mu \mathrm{mol}, 250 \mathrm{mCi}$; Amersham International, Little Chalfont, UK), using T4 polynucleotide kinase (Roche, Basel, Switzerland). Oligonucleotide sequence was 5'-TCTGTACGTGACCACACTCACCTC-3'. For each extract, $10 \mu \mathrm{g}$ was incubated for $20 \mathrm{~min}$ with $20000 \mathrm{cpm}$ of $\left[{ }^{32} \mathrm{P}\right]$-labeled double-stranded oligonucleotide at $4^{\circ} \mathrm{C}$. In the supershift assay, nuclear extracts were pre-incubated for $30 \mathrm{~min}$ at room temperature with $2 \mu \mathrm{L}$ of an anti-HIF$1 \alpha$ antibody (Millipore); the reaction mixture containing the $\left[{ }^{32} \mathrm{P}\right]$-labeled double-stranded oligonucleotide was then added. The DNA-protein complex was separated on a non denaturating $4 \%$ polyacrylamide gel in TBE buffer $(0.4 \mathrm{~mol} / \mathrm{L}$ Tris, $0.45 \mathrm{~mol} / \mathrm{L}$ boric acid, $0.5 \mathrm{~mol} / \mathrm{L}$ EDTA, $\mathrm{pH}$ 8.0). After electrophoresis, the gel was dried and autoradiographed by exposure to X-ray film for $24 \mathrm{~h}$.

\section{Gene silencing}

$2 \times 10^{5}$ cells were transfected with $400 \mathrm{nmol} / \mathrm{L}$ of 20-25 nucleotide non targeting scrambled siRNA (Control siRNA-A, Santa Cruz Biotechnology Inc.) or 
specific siRNA pools for CAXII, CAIX or HIF-1 $\alpha$ (Santa Cruz Biotechnology Inc.), following the manufacturer's instructions. To verify the silencing efficacy, $24 \mathrm{~h}$ after the transfection the levels of mRNAs were checked by qRTPCR, $48 \mathrm{~h}$ after the transfection the expression of proteins was checked by Western blotting. To verify the absence of cell toxicity after silencing, cell proliferation, apoptosis and viability was measured, as reported below.

\section{Cell proliferation, apoptosis and senescence}

To evaluate cell proliferation, $5 \times 10^{5}$ cells were grown on sterile glass coverslips, rinsed and fixed with $4 \%$ $\mathrm{w} / \mathrm{v}$ paraformaldehyde for $15 \mathrm{~min}$, then permeabilized with $0.1 \% \mathrm{v} / \mathrm{v}$ Triton-X100 for $5 \mathrm{~min}$ on ice, washed three times with PBS and stained with an anti-Ki67 antibody (Abcam) for $1 \mathrm{~h}$ at room temperature. After washing, samples were incubated with an AlexaFluor 488-conjugated secondary antibody (Millipore) for $1 \mathrm{~h}$ and re-washed. Finally, cells were stained with PI $(1 \mu \mathrm{g} / \mathrm{ml})$ to counterstain the nuclei, and washed again. The coverslips were mounted with $4 \mu \mathrm{L}$ of Gel Mount Aqueous Mounting and examined by confocal microscopy as detailed above. Early and late apoptosis was measured by the Annexin V/Propidium Iodide Apoptosis Detection Kit (Sigma Chemical Co.). $1 \times 10^{5}$ cells were analyzed with a FACS-Calibur flow cytometer (Becton Dickinson). The percentage of cells positive to annexin V-FITC and PI was calculated with the Cell Quest software (Becton Dickinson). Cell senescence was evaluated on $5 \times 10^{5}$ cells fixed and stained with the Senescence Cells Histochemical Staining Kit (Sigma Chemical Co.), following the manufacturer's instruction. Samples were examined with a Leica DC100 fluorescence microscope (Leica Microsystems GmbH, Wetzlar, Germany). For each experimental point, a minimum of five microscopic fields were examined.

\section{Intracellular doxorubicin accumulation}

Doxorubicin content was measured fluorimetrically as detailed elsewhere [55]. The results were expressed as $\mathrm{nmol}$ doxorubicin/mg cell proteins, according to a titration curve previously set.

\section{Cell viability}

Cell viability was evaluated by measuring the percentage of cells stained with neutral red dye, as reported previously [49]. The viability of untreated cells was considered $100 \%$; the results were expressed as percentage of viable cells in each experimental condition versus untreated cells.

\section{ATPase Pgp activity}

The assay was performed on Pgp-enriched membrane vesicles as detailed elsewhere [56]. Verapamil
$(10 \mu \mathrm{mol} / \mathrm{L})$ was added to the reaction mix to achieve a maximal activation of the Pgp ATPase activity. Results were expressed as nmol hydrolyzed phosphate $(\mathrm{Pi}) / \mathrm{min} /$ mg proteins, according to the titration curve previously prepared.

\section{Intracellular $\mathrm{pH}\left(\mathrm{pH}_{\mathrm{i}}\right)$ measurement}

The pHi was measured by incubating whole cells with $5 \mu \mathrm{mol} / \mathrm{L}$ of 2',7'-bis-(2-carboxyethyl)-5-(and-6)carboxyfluorescein acetoxymethyl ester (BCECF-AM) for $15 \mathrm{~min}$ at $37^{\circ} \mathrm{C}$ and reading the intracellular fluorescence by a FACSCalibur flow cytometer (Becton Dickinson). The intracellular fluorescence was converted into $\mathrm{pH}$ units according to a titration curve, as described previously [41].

\section{Statistical analysis}

All data in text and figures are provided as means \pm SD. The results were analyzed by a one-way Analysis of Variance (ANOVA). A $p<0.05$ was considered significant.

\section{ACKNOWLEDGEMENTS}

This work was supported by grants from the Italian Association for Cancer Research (AIRC; grant MFAG 11475 and IG 15232), the Italian Ministry of University and Research ("Future in Research program" FIRB 2012, grant RBFR12SOQ1) to C.R.; the Swiss National Science Foundation (SNSF, 31003A_135805) to B.W.

$\mathrm{JK}$ is fellow of the Italian Foundation for Cancer Research (FIRC).

We thank Erika Ortolan (Department of Medical Sciences, University of Torino) and Costanzo Costamagna (Department of Oncology, University of Torino) for the technical assistance.

\section{Conflict of interest}

None.

\section{REFERENCES}

1. Gottesman MM, Fojo T, Bates SE. Multidrug resistance in cancer: role of ATP-dependent transporters. Nat Rev Cancer. 2002; 2:48-58.

2. Borst P, Evers R, Kool M, Wijnholds J. A family of drug transporters: the multidrug resistance-associated proteins. J Natl Cancer Inst. 2000; 92:1295-1302.

3. Polgar O, Bates SE. ABC transporters in the balance: is there a role in multidrug resistance? Biochem Soc Trans. 2005; 33:241-245.

4. Brózik A, Hegedüs C, Erdei Z, Hegedus T, ÖzvegyLaczka C, Szakács G, Sarkadi B. Tyrosine kinase inhibitors as modulators of ATP binding cassette multidrug 
transporters: substrates, chemosensitizers or inducers of acquired multidrug resistance? Expert Opin Drug Metab Toxicol. 2011; 7:623-642.

5. Sarkadi B, Homolya L, Szakács G, Váradi A. Human multidrug resistance $\mathrm{ABCB}$ and $\mathrm{ABCG}$ transporters: participation in a chemoimmunity defense system. Physiol Rev. 2006; 86:1179-1236.

6. Ueda K. ABC proteins protect the human body and maintain optimal health. Biosci Biotechnol Biochem. 2011; 75:401-409.

7. Zutz A, Gompf S, Schägger H, Tampé R. Mitochondrial $\mathrm{ABC}$ proteins in health and disease. Biochim Biophys Acta. 2009; 1787:681-690.

8. Cain JW, Hauptschein RS, Stewart JK, Bagci T, Sahagian GG, Jay DG. Identification of CD44 as a surface biomarker for drug resistance by surface proteome signature technology. Mol Cancer Res. 2011; 9:637-647.

9. Li K, Sun Z, Zheng J, Lu Y, Bian Y, Ye M, Wang X, Nie Y, Zou H, Fan D. In-depth research of multidrug resistance related cell surface glycoproteome in gastric cancer. J Proteomics. 2013; 82:130-140.

10. Sharom FJ. Complex Interplay between the P-Glycoprotein Multidrug Efflux Pump and the Membrane: Its Role in Modulating Protein Function. Front Oncol. 2014; 4:e41.

11. Rao PS, Mallya KB, Srivenugopal KS, Balaji KC, Rao US. RNF2 interacts with the linker region of the human P-glycoprotein. Int J Oncol. 2006; 29:1413-1419.

12. Katayama K, Noguchi K, Sugimoto Y. FBXO15 regulates P-glycoprotein/ABCB1 expression through the ubiquitinproteasome pathway in cancer cells. Cancer Sci. 2013; 104:694-702.

13. Kopecka J, Campia I, Brusa D, Doublier S, Matera L, Ghigo D, Bosia A, Riganti C. Nitric oxide and P-glycoprotein modulate the phagocytosis of colon cancer cells. J Cell Mol Med. 2011; 15:1492-1504.

14. Xie Y, Burcu M, Linn DE, Qiu Y, Baer MR. Pim-1 kinase protects P-glycoprotein from degradation and enables its glycosylation and cell surface expression. Mol Pharmacol. 2010; 78:310-318.

15. Ewing RM, Chu P, Elisma F, Li H, Taylor P, Climie S, McBroom-Cerajewski L, Robinson MD, O’Connor L, Li M, Taylor R, Dharsee M, Ho Y, et al. Large-scale mapping of human protein-protein interactions by mass spectrometry. Mol Syst Biol. 2007; 3:e89.

16. Agrawal P, Yu K, Salomon AR, Sedivy JM. Proteomic profiling of Myc-associated proteins. Cell Cycle. 2010; 9:4908-4921.

17. Cai C, Chen J. Overexpression of caveolin-1 induces alteration of multidrug resistance in Hs578T breast adenocarcinoma cells. Int J Cancer. 2004; 111:522-529.

18. Wang J, Huo K, Ma L, Tang L, Li D, Huang X, Yuan Y, Li C, Wang W, Guan W, Chen H, Jin C, Wei J, et al. Toward an understanding of the protein interaction network of the human liver. Mol Syst Biol. 2011; 7:e536.
19. Li L, Wei XH, Pan YP, Li HC, Yang H, He QH, Pang Y, Shan Y, Xiong FX, Shao GZ, Zhou RL. LAPTM4B: a novel cancer-associated gene motivates multidrug resistance through efflux and activating PI3K/AKT signaling. Oncogene. 2010; 29:5785-5795.

20. Pastorekova S, Zatovicova M, Pastorek J. Cancer-associated carbonic anhydrases and their inhibition. Curr Pharm Des. 2008; 14:685-698.

21. Comerford KM, Wallace TJ, Karhausen J, Louis NA, Montalto MC, Colgan SP. Hypoxia-inducible factor-1dependent regulation of the multidrug resistance (MDR1) gene. Cancer Res. 2002; 62:3387-3394.

22. Gondi G, Mysliwietz J, Hulikova A, Jen JP, Swietach P, Kremmer E, Zeidler R. Antitumor efficacy of a monoclonal antibody that inhibits the activity of cancer-associated carbonic anhydrase XII. Cancer Res. 2013; 73:6494-6503.

23. Luo F, Paranjpe PV, Guo A, Rubin E, Sinko P. Intestinal transport of irinotecan in Caco-2 cells and MDCK II cells overexpressing efflux transporters Pgp, cMOAT and MRP1. Drug Metab Dispos. 2002; 30:763-770.

24. Güzel-Akdemir Ö, Akdemir A, Isik S, Vullo D, Supuran CT. o-Benzenedisulfonimido-sulfonamides are potent inhibitors of the tumor-associated carbonic anhydrase isoforms CA, IX, and CA, XII. Bioorg Med Chem. 2013; 21:1386-1391.

25. Chiche J, Ilc K, Laferrière J, Trottier E, Dayan F, Mazure NM, Brahimi-Horn MC, Pouysségur J. Hypoxiainducible carbonic anhydrase IX and XII promote tumor cell growth by counteracting acidosis through the regulation of the intracellular pH. Cancer Res. 2009; 69:358-368.

26. Rafalko A, Iliopoulos O, Fusaro VA, Hancock W, Hincapie M. Immunoaffinity enrichment and liquid chromatography-selected reaction monitoring mass spectrometry for quantitation of carbonic anhydrase 12 in cultured renal carcinoma cells. Anal Chem. 2010; 82:8998-9005.

27. Hynninen P, Vaskivuo L, Saarnio J, Haapasalo H, Kivelä J, Pastoreková S, Pastorek J, Waheed A, Sly WS, Puistola U, Parkkila S. Expression of transmembrane carbonic anhydrases IX and XII in ovarian tumours. Histopathology. 2006; 49:594-602.

28. Kivelä A, Parkkila S, Saarnio J, Karttunen TJ, Kivelä J, Parkkila AK, Waheed A, Sly WS, Grubb JH, Shah G, Türeci O, Rajaniemi H. Expression of a novel transmembrane carbonic anhydrase isozyme XII in normal human gut and colorectal tumors. Am J Pathol. 2000; 156:577-584.

29. Ulmasov B, Waheed A, Shah GN, Grubb JH, Sly WS, Tu C, Silverman DN. Purification and kinetic analysis of recombinant $\mathrm{CA}$, XII, a membrane carbonic anhydrase overexpressed in certain cancers. Proc Natl Acad Sci USA. 2000; 97:14212-14217.

30. Riganti C, Castella B, Kopecka J, Campia I, Coscia M, Pescarmona G, Bosia A, Ghigo D, Massaia M. Zoledronic acid restores doxorubicin chemosensitivity and immunogenic cell death in multidrug-resistant human cancer cells. PLoS One. 2013; 8:e60975. 
31. Deavall DG, Martin EA, Horner JM, Roberts R. Druginduced oxidative stress and toxicity. J Toxicol. 2012; 2012:e645460.

32. Cho KH, Choi MJ, Jeong KJ, Kim JJ, Hwang MH, Shin SC, Park CG, Lee HY. A ROS/STAT3/HIF-1 $\alpha$ signaling cascade mediates EGF-induced TWIST1 expression and prostate cancer cell invasion. Prostate. 2014; 74:528-536.

33. Watson PH, Chia SK, Wykoff CC, Han C, Leek RD, Sly WS, Gatter KC, Ratcliffe P, Harris AL. Carbonic anhydrase XII is a marker of good prognosis in invasive breast carcinoma. Br J Cancer. 2003; 88:1065-1070.

34. Ilie MI, Hofman V, Ortholan C, Ammadi RE, Bonnetaud C, Havet K, Venissac N, Mouroux J, Mazure NM, Pouysségur J, Hofman P. Overexpression of carbonic anhydrase XII in tissues from resectable non-small cell lung cancers is a biomarker of good prognosis. Int J Cancer. 2011; 128:1614-1623.

35. Haapasalo J, Hilvo M, Nordfors $K$, Haapasalo $H$, Parkkila S, Hyrskyluoto A, Rantala I, Waheed A, Sly WS, Pastorekova S, Pastorek J, Parkkila AK. Identification of an alternatively spliced isoform of carbonic anhydrase XII in diffusely infiltrating astrocytic gliomas. Neuro Oncol. 2008; 10:131-138.

36. Chien $\mathrm{MH}$, Ying $\mathrm{TH}$, Hsieh $\mathrm{YH}$, Lin $\mathrm{CH}$, Shih $\mathrm{CH}$, Wei LH, Yang SF. Tumor-associated carbonic anhydrase XII is linked to the growth of primary oral squamous cell carcinoma and its poor prognosis. Oral Oncol. 2012; 48:417-423.

37. Gieling RG, Babur M, Mamnani L, Burrows N, Telfer BA, Carta F, Winum JY, Scozzafava A, Supuran CT, Williams KJ. Antimetastatic effect of sulfamate carbonic anhydrase IX inhibitors in breast carcinoma xenografts. J Med Chem. 2012; 55:5591-5600.

38. Whittington DA, Waheed A, Ulmasov B, Shah GN, Grubb JH, Sly WS, Christianson DW. Crystal structure of the dimeric extracellular domain of human carbonic anhydrase XII, a bitopic membrane protein overexpressed in certain cancer tumor cells. Proc Natl Acad Sci USA. 2001; 98:9545-9550.

39. Betof AS, Rabbani ZN, Hardee ME, Kim SJ, Broadwater G, Bentley RC, Snyder SA, Vujaskovic Z, Oosterwijk E, Harris LN, Horton JK, Dewhirst MW, Blackwell KL. Carbonic anhydrase IX is a predictive marker of doxorubicin resistance in early-stage breast cancer independent of HER2 and TOP2A amplification. Br J Cancer. 2012; 106:916-922.

40. Aänismaa P, Seelig A. P-Glycoprotein kinetics measured in plasma membrane vesicles and living cells. Biochemistry. 2007; 46:3394-3404.

41. Miraglia E, Viarisio D, Riganti C, Costamagna C, Ghigo D, Bosia A. $\mathrm{Na}^{+} / \mathrm{H}^{+}$exchanger activity is increased in doxorubicin-resistant human colon cancer cells and its modulation modifies the sensitivity of the cells to doxorubicin. Int $\mathrm{J}$ Cancer. 2005; 115:924-929.
42. Ahlskog JK, Dumelin CE, Trüssel S, Mårlind J, Neri D. In vivo targeting of tumor-associated carbonic anhydrases using acetazolamide derivatives. Bioorg Med Chem Lett. 2009; 19:4851-4856.

43. Gieling RG, Parker CA, De Costa LA, Robertson N, Harris AL, Stratford IJ, Williams KJ. Inhibition of carbonic anhydrase activity modifies the toxicity of doxorubicin and melphalan in tumour cells in vitro. J Enzyme Inhib Med Chem. 2013; 28:360-369.

44. Salmon AJ, Williams ML, Wu QK, Morizzi J, Gregg D, Charman SA, Vullo D, Supuran CT, Poulsen SA. Metallocene-based inhibitors of cancer-associated carbonic anhydrase enzymes IX and XII. J Med Chem. 2012; 55:5506-5517.

45. Tars K, Vullo D, Kazaks A, Leitans J, Lends A, Grandane A, Zalubovskis R, Scozzafava A, Supuran CT. Sulfocoumarins (1,2-benzoxathiine-2,2-dioxides): a class of potent and isoform-selective inhibitors of tumor-associated carbonic anhydrases. J Med Chem. 2013; 56:293-300.

46. D'Ascenzio M, Carradori S, De Monte C, Secci D, Ceruso M, Supuran CT. Design, synthesis and evaluation of $\mathrm{N}$-substituted saccharin derivatives as selective inhibitors of tumor-associated carbonic anhydrase XII. Bioorg Med Chem. 2014; 22:1821-1831.

47. Morris JC, Chiche J, Grellier C, Lopez M, Bornaghi LF, Maresca A, Supuran CT, Pouysségur J, Poulsen SA. Targeting hypoxic tumor cell viability with carbohydratebased carbonic anhydrase IX and XII inhibitors. J Med Chem. 2011; 54:6905-6918.

48. Fonseca NA, Gregório AC, Valério-Fernandes A, Simões S, Moreira JN. Bridging cancer biology and the patients' needs with nanotechnology-based approaches. Cancer Treat Rev. 2014; 40:626-635.

49. Gelsomino G, Corsetto PA, Campia I, Montorfano G, Kopecka J, Castella B, Gazzano E, Ghigo D, Rizzo AM, Riganti C. Omega 3 fatty acids chemosensitize multidrug resistant colon cancer cells by down-regulating cholesterol synthesis and altering detergent resistant membranes composition. Mol Cancer. 2013; 12:e137.

50. Kopecka J, Campia I, Olivero P, Pescarmona G, Ghigo D, Bosia A, Riganti C. A LDL-masked liposomal-doxorubicin reverses drug resistance in human cancer cells. J Contr Rel. 2011; 149:196-205.

51. Serra M, Scotlandi K, Manara MC, Maurici D, Lollini PL, De Giovanni C, Toffoli G, Baldini N. Establishment and characterization of multidrug-resistant human osteosarcoma cell lines. Anticancer Res. 1993; 13:323-329.

52. Bausch-Fluck D, Hofmann A, Wollscheid B. Cell surface capturing technologies for the surfaceome discovery of hepatocytes. Methods Mol Biol. 2012; 909:1-16.

53. De Boo S, Kopecka J, Brusa D, Gazzano E, Matera L, Ghigo D, Bosia A, Riganti C. iNOS activity is necessary for the cytotoxic and immunogenic effects of doxorubicin in human colon cancer cells. Mol Cancer. 2009; 8:e108. 
54. Campia I, Gazzano E, Pescarmona G, Ghigo D, Bosia A, Riganti C. Digoxin and ouabain increase the synthesis of cholesterol in human liver cells. Cell Mol Life Sci. 2009; 66:1580-1594.

55. Riganti C, Miraglia E, Viarisio D, Costamagna C, Pescarmona G, Ghigo D, Bosia A. Nitric oxide reverts the resistance to doxorubicin in human colon cancer cells by inhibiting the drug efflux. Cancer Res. 2005; 65:516-525.

56. Kopecka J, Salzano G, Campia I, Lusa S, Ghigo D, De Rosa G, Riganti C. Insights in the chemical components of liposomes responsible for P-glycoprotein inhibition. Nanomedicine. 2014; 10:77-87. 